\title{
Preparation of N-Doped Composite Shell Encapsulated Iron Nanoparticles and Their Magnetic, Adsorptive, and Photocatalytic Properties
}

\author{
Caijing Shi, ${ }^{1}$ Lan Cui, ${ }^{2}$ Kui Lin, ${ }^{2}$ Qianjin Guo, ${ }^{2}$ Fan Zhang, ${ }^{1}$ Fengxiang Hu, \\ Sayyar Ali Shah, ${ }^{1}$ Xitao Wang, ${ }^{3}$ Xiaoping Chen, ${ }^{2}$ and Shen Cui ${ }^{1}$ \\ ${ }^{1}$ Department of Chemistry, School of Science, Tianjin University, Tianjin 300072, China \\ ${ }^{2}$ Center of Analysis, Tianjin University, Tianjin 300072, China \\ ${ }^{3}$ Department of Catalysis, School of Chemical Engineering and Technology, Tianjin University, Tianjin 300072, China
}

Correspondence should be addressed to Shen Cui; cuishen@tju.edu.cn

Received 23 July 2016; Revised 28 December 2016; Accepted 5 January 2017; Published 20 February 2017

Academic Editor: Pedro D. Vaz

Copyright (C) 2017 Caijing Shi et al. This is an open access article distributed under the Creative Commons Attribution License, which permits unrestricted use, distribution, and reproduction in any medium, provided the original work is properly cited.

\begin{abstract}
The N-doped composite shell encapsulated iron nanoparticles (CSEINPs) were prepared by DC arc discharge under nitrogen at $800^{\circ} \mathrm{C}$, using the anode with high Fe content and good homogeneity. The morphology, microstructure, composition, and some properties of the N-doped CSEINPs were characterized by various characterization techniques. The results revealed that the shells of the $\mathrm{N}$-doped CSEINPs were composed of homogeneously amorphous structure containing $\mathrm{C}, \mathrm{Fe}, \mathrm{O}$, and $\mathrm{N}$ elements; the saturation magnetization $(M s)$ and coercivity $(H c)$ of them at room temperature were $130 \mathrm{emu} / \mathrm{g}$ and $194 \mathrm{Oe}$, respectively. Due to the surface structure and the electrostatic interaction, the N-doped CSEINPs are employed to remove methylene blue (MB) from the waste solution, and they exhibited high adsorption properties and photocatalytic activity under irradiation of visible light (IVL). The kinetics of adsorption of $\mathrm{MB}$ on the $\mathrm{N}$-doped CSEINPs was investigated and the recycling test was carried out. The formation mechanism of the N-doped CSEINPs is discussed briefly.
\end{abstract}

\section{Introduction}

Magnetic nanoparticles exhibit some important properties and have many applications, like magnetic recording materials [1], microwave absorber [2], magnetic hyperthermia treatment [3], drug delivery [4], catalyst supports [5], organic dye adsorbent [6], lithium-ion battery anode [7], and so forth. The magnetic nanoparticles, however, usually have high chemical activity and are easily aggregated or oxidized in the air, leading to the loss of magnetism and some unique properties. Carbon encapsulated magnetic nanoparticles (CEM$\mathrm{NPs}$ ) have attracted increasing interests, as carbon layers can not only protect the magnetic nanoparticles from oxidation and magnetic degradation, but also inhibit their aggregation and promote phase formation by weakening the magnetic coupling [8]. Various methods, such as hydrothermal reaction [9], chemical vapor deposition [10], laser ablation [11], sol-gel [12], spray pyrolysis [13], and arc discharge [14], have been used to prepare CEMNPs.

The carbon shell usually consists of graphite structure, amorphous carbon, or turbostratic structure. But, sometimes, the shell may be a composite one containing several different substances. Zhang et al. prepared the carbon encapsulated iron nanoparticles by DC arc discharge and found that the shell contained $\mathrm{C}, \mathrm{Fe}$, and $\mathrm{O}$ elements and its structure consisted of three parts; that is, the inside part was nongraphite, the middle one was incomplete graphite, and the outside one was amorphous carbon [15]. Kim et al. employed the process of chemical vapor condensation to prepare the carbon-coated Fe nanocapsules, and the shell was a double layer structure, that is, $\mathrm{Fe}_{3} \mathrm{C}$ and graphite layers [16]. Zhang et al. synthesised the core-shell-shell composite submicrospheres $\left(\mathrm{Fe}_{3} \mathrm{O}_{4} @ \mathrm{SiO}_{2} @ \mathrm{MnO}_{2}\right)$ by homogeneous precipitation of $\mathrm{MnO}_{2}$ on $\mathrm{Fe}_{3} \mathrm{O}_{4} @ \mathrm{SiO}_{2}$ spheres, which were 
prepared by a modified sol-gel method in the presence of $\mathrm{Fe}_{3} \mathrm{O}_{4}$ particles, and the submicrospheres showed superparamagnetic property ( $M s$ value $29.41 \mathrm{eum} / \mathrm{g}$ ), high activity of chemical adsorption, and good stability for the decolouration of organic dye [17].

Organic dyes with complex aromatic structures and xenobiotic properties seriously induce water pollution and are difficult to be degraded, leading to very harmful effects on aquatic lives and human beings [18]. For example, MB can cause eye burns of humans and animals and also gives rise to dyspnea, tachycardia, and mental confusion [19]. Therefore, it is necessary to remove MB from waste solution before discharge. To date, the processes of adsorption and photodegradation, in which the magnetic materials are used, are the most well-developed methods to remove organic dyes from waste water. Qu et al. used B-Fe3O4@C composites as adsorbent for the removal of MB. The adsorption capacity at equilibrium increases from 26.1 to $40.88 \mathrm{mg} / \mathrm{g}$, with an increase in the initial dye concentration from 14 to $52 \mathrm{mg} / \mathrm{L}$ [20]. Wang et al. employed the graphite carbon encapsulated $\mathrm{Fe}_{3} \mathrm{C}$ nanoparticles ( $\mathrm{Fe}_{3} \mathrm{C} @ \mathrm{GC} \mathrm{NPs}$ ) to remove $\mathrm{MB}$. The $\mathrm{Fe}_{3} \mathrm{C} @ \mathrm{GC}$ NPs exhibited ferrimagnetic behavior at room temperature, with a value of $M s$ of $61.5 \mathrm{emu} / \mathrm{g}$. The adsorption capacity of $\mathrm{MB}$ on $\mathrm{Fe}_{3} \mathrm{C} @ \mathrm{GC}$ NPs was $33.1 \mathrm{mg} / \mathrm{g}$ [21]. Bai et al. fabricated the ferrite hybrids $\left(\mathrm{MFe}_{2} \mathrm{O}_{4}, \mathrm{M}=\mathrm{Mn}, \mathrm{Zn}, \mathrm{Co}\right.$, and $\mathrm{Ni}$ ) supported on the reduced graphene oxide (RGO). The maximum adsorption capacities of $\mathrm{RhB}$ and $\mathrm{MB}$ on RGO- $\mathrm{MFe}_{2} \mathrm{O}_{4}$ were $22.52 \mathrm{mg} / \mathrm{g}$ and $34.72 \mathrm{mg} / \mathrm{g}$, with the initial dyes concentration of $10 \mathrm{mg} / \mathrm{L}$. The different RGO$\mathrm{MFe}_{2} \mathrm{O}_{4}$ hybrids decomposed over $85 \%$ of $\mathrm{RhB}$ and $\mathrm{MB}$ after $180 \mathrm{~min}$ under tungsten lamp of $500 \mathrm{~W}$ [22]. Mansour used the prepared $\alpha-\mathrm{Fe}_{2} \mathrm{O}_{3}$ nanoparticles as catalyst and hydrogen peroxide as oxidant to degrade MB under UV light, and about $98 \%$ of MB was degraded within about $100 \mathrm{~min}$ [23]. Rashid et al. reported that the magnetic core-shell-shell nanoparticles $\mathrm{Fe}_{3} \mathrm{O}_{4} / \mathrm{SiO}_{2} / \mathrm{TiO}_{2}$ showed high photocatalytic activity toward 2-chlorophenol in wastewater. They also carried out the leaching test to check the robustness of the nanoparticles in aqueous medium [24].

In this work, we present the preparation of $\mathrm{N}$-doped CSEINPs by DC arc discharge. Their morphology, structure, composition, and magnetic properties were investigated. The $\mathrm{N}$-doped CSEINPs were used as adsorbent to remove MB from its aqueous solution and their photocatalytic activity was also investigated. They exhibited high adsorptive capacity and photocatalytic activity for the removal and photodegradation of $\mathrm{MB}$, respectively, and may be the highly efficient and environmentally friendly candidate for the treatment of waste water. The possible mechanism for the process of formation of N-doped CSEINPs is briefly discussed.

\section{Experimental}

2.1. Preparation of Anode. Iron (III) oxide (purity $>99$ wt.\%) and graphite (purity $>99.99 \mathrm{wt} . \%$ ) powders were mixed at the weight ratio of $9: 1$. The equal amount (50 wt.\%) of binder (syrup, mainly consisting of glucose) was mixed with the above mixture and then dried at ca. $150^{\circ} \mathrm{C}$. After cooling to room temperature, the dried product was ground into powders and then filled in a mold, and subsequently the filler was compressed under $\sim 3 \mathrm{MPa}$ to form a composite rod. Finally, the rod was carbonized at $800^{\circ} \mathrm{C}$ under argon atmosphere for one hour and a cylindrical anode $(\sim 6.6 \mathrm{~mm}$ diameter and $\sim 50 \mathrm{~mm}$ length) was obtained. The phase composition of the as-prepared anode mainly includes $\mathrm{Fe}$, graphite carbon, $\mathrm{FeO}$, and a small amount of $\mathrm{Fe}_{3} \mathrm{O}_{4}$ (see Figure S1 in Supplementary Material available online at https://doi.org/10.1155/2017/7868121). The content of Fe in the anode was ca. 75.5 wt.\% (see Figure S2 and the calculations in Supplementary Material).

2.2. DC Arc Discharge. The arc discharge apparatus is similar to that reported in [25], but some modifications were made [26]. The cathode was a pure graphite rod $(15 \mathrm{~mm}$ diameter and $10 \mathrm{~mm}$ length). The intake temperature of nitrogen was chosen as $800^{\circ} \mathrm{C}$ because of the considerations of the decrease of temperature gradient in the environment around arc discharge zone, the possible decomposition of nitrogen, and the lifetime of the heating apparatus. The arc discharge voltage and current between anode and cathode were about 30-40 V and 30-40 A, respectively. The gap between two electrodes was kept at a distance of $1-2 \mathrm{~mm}$ by manually advancing the anode, while keeping the cathode fixed. The duration of arc discharge was $50 \mathrm{~s}$. The products A-E were collected from the different parts inside the arc discharge chamber (ADC), as described previously [25]. The main morphologies of the products $\mathrm{A}, \mathrm{B}, \mathrm{D}$, and $\mathrm{E}$ are similar and all of them mainly consist of the nanoparticles, as shown in Figure 1. The insets in Figure 1 show the core-shell structure of nanoparticles in the products $\mathrm{A}, \mathrm{B}, \mathrm{D}$, and $\mathrm{E}$. The product $\mathrm{C}$ deposited on the top of cathode mainly consists of the nanosheets (see Figure S3 in Supplementary Material) and may be presented in another paper. As the research emphasis of this work is the nanoparticles and the amount of the product $B$ is the most among products $A, B, D$, and $E$, all of the characterizations were focused on product $B$. The schematic diagram for the preparation of product B is shown in Figure 2.

2.3. Characterizations. Product B was characterized by using high-resolution transmission electron microscope (HRTEM, TECNAI G ${ }^{2}$ F20, Philips), energy dispersive X-ray (EDX) spectroscope, and electron energy loss spectroscope (EELS, GIF 863 Tridiem, detectable limit $0.05-0.1$ at.\%) both of which were equipped with HRTEM, X-ray diffractometer (XRD, Pert PRO, Panalytical), Fourier Transform Infrared Spectrometer (FTIR, Perkin-Elmer Spectrum GX), and thermogravimetry-differential scanning calorimeter (TGDSC, STA409PC, Netzsch). The magnetic properties were measured by using Physical Property Measurement System (QUANYUM DESIGE PPMS-9, Quantum Design) at room temperature. The adsorptive properties of the $\mathrm{N}$-doped CSEINPs were measured by using UV-vis spectrophotometer (TU-1901, Phenix) and their photocatalytic activity was evaluated by the degradation of MB under IVL.

2.4. Adsorption Experiment of MB. $25 \mathrm{mg} \mathrm{N}$-doped CSEINPs was add to $50 \mathrm{~mL} \mathrm{MB}$ aqueous solution $(10-60 \mathrm{mg} / \mathrm{L})$ and the mixture was shaken under natural light for some time. 


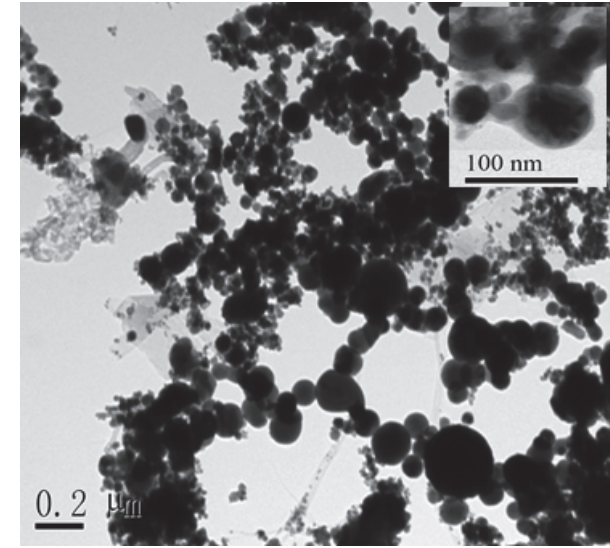

(a)

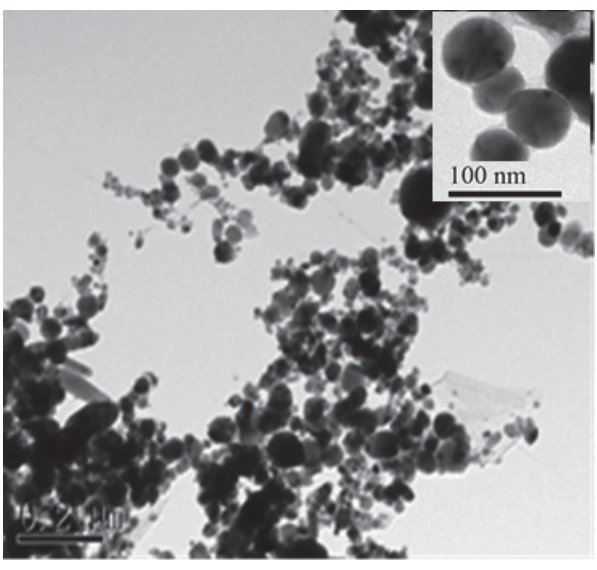

(c)

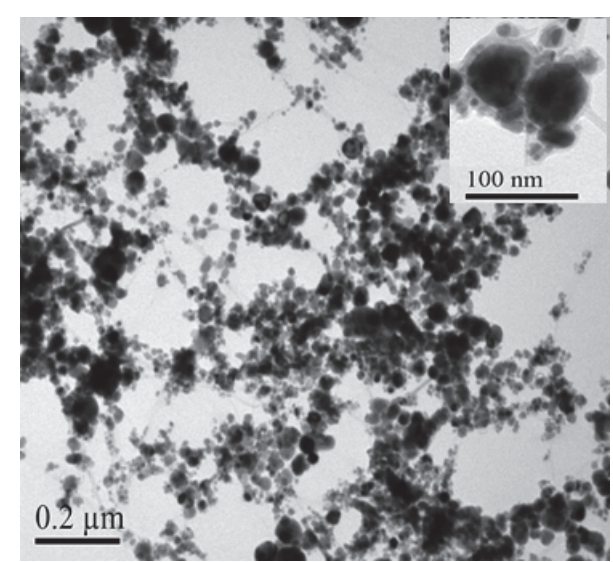

(b)

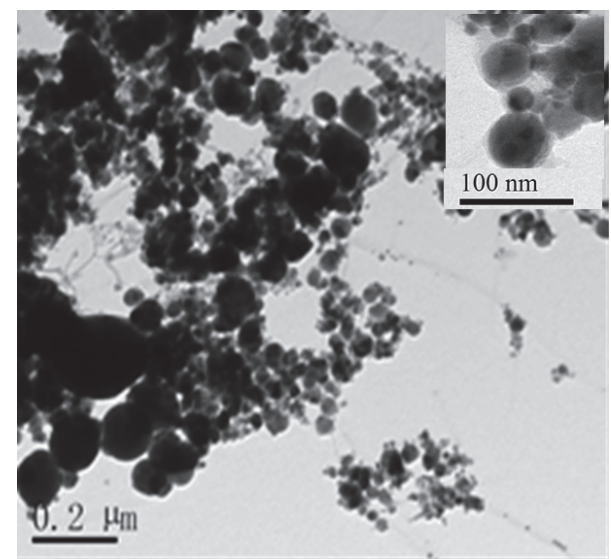

(d)

FIGURE 1: TEM images of products (a) A, (b) B, (c) D, and (d) E. The inserts are the images at higher magnification and show the core-shell structure of the nanoparticles.
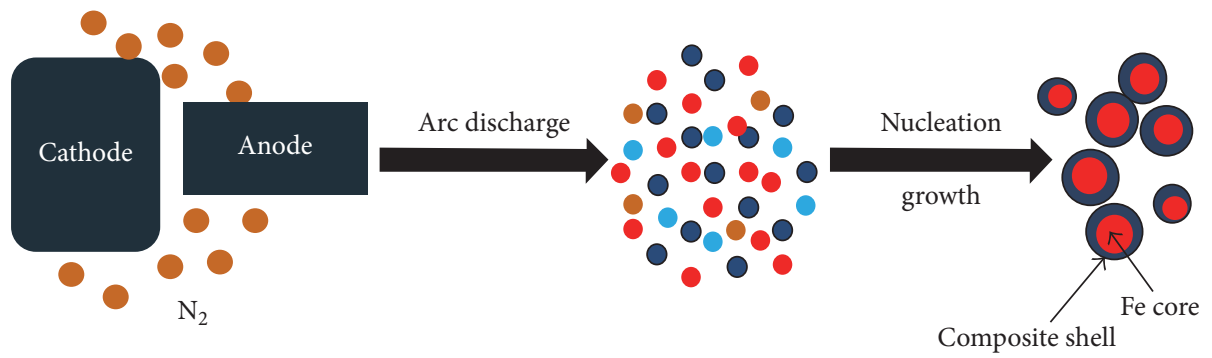

$\begin{array}{ll}\mathrm{C} & \mathrm{O} \\ \mathrm{Fe} & \mathrm{N}\end{array}$

FIGURE 2: Schematic illustration of preparation process of product B [27].

Subsequently, the suspension was handled with a magnet and then the $\mathrm{MB}$ concentrations were measured with $\mathrm{UV}$ vis spectrophotometer. The amounts of MB adsorbed on the $\mathrm{N}$-doped CSEINPs were calculated from its concentrations before and after adsorption at room temperature.
The removal (\%) of $\mathrm{MB}$ was calculated based on the following equation [6]:

$$
\operatorname{Removal}(\%)=\left(1-\frac{C_{t}}{C_{0}}\right) \times 100 \%
$$


where $C_{0}$ and $C_{t}$ are the concentrations $(\mathrm{mg} / \mathrm{L})$ of the beginning and time $t$ of $\mathrm{MB}$, respectively.

The adsorbed amount $(q)$ of $\mathrm{MB}$ was calculated using the following equation [6]:

$$
q=\left(C_{0}-C_{t}\right) \frac{V}{m}
$$

where $m$ is the mass of adsorbent $(g)$ and $V$ is the volume of solution $(L)$.

2.5. Photocatalytic Degradation Experiment of $M B$. The visible light was obtained by a $500 \mathrm{~W}$ xenon lamp (Institute of Electric Light Source, Beijing) with a $420 \mathrm{~nm}$ cutoff filter. $18 \mathrm{mg} \mathrm{N}$-doped CSEINPs was dispersed in $50 \mathrm{~mL} \mathrm{MB}$ aqueous solution $(10 \mathrm{mg} / \mathrm{L})$. The suspension was magnetically stirred in the dark for $60 \mathrm{~min}$ to reach the adsorptiondesorption equilibrium. After the light was turned on, $4 \mathrm{~mL}$ suspension was sampled at certain intervals and then centrifuged to remove the nanoparticles. The filtrates were analyzed by recording the variations at the absorption band of $664 \mathrm{~nm}$ in the UV-vis spectra of MB.

\section{Results and Discussion}

Figure 3(a) shows the HRTEM image of product $B$ at low magnification, in which many relatively dispersed and approximately spherical nanoparticles can be observed. It can be clearly seen that the nanoparticles have typical coreshell structure (Figure 3(b)), that is, the light black core and gray shell. The diameter of nanoparticle A is about $91 \mathrm{~nm}$ and the thickness of its shell is about $6 \mathrm{~nm}$. The result of EDX measurement shows that the atomic percent contents of the elements $\mathrm{C}, \mathrm{Fe}, \mathrm{O}$, and $\mathrm{N}$ at the region inside the white circle in Figure 3(b) are 15.05\%, 68.87\%, 5.63\%, and $10.46 \%$, respectively (see Figure S4 in Supplementary Material). Figures 3(c) and 3(d) are the enlarged images of the upper and lower shells of nanoparticle A in Figure 3(b), respectively. Both of the shells are composed of disordered structure and there is no layered structure of graphite. The histogram of size distribution of the nanoparticles is shown in Figure 3(e). The diameters of approximately $95.6 \%$ nanoparticles are in the range of 3-44 $\mathrm{nm}$ and the average diameter is about $20.8 \mathrm{~nm}$.

As the temperature at the center of arc discharge zone may reach $3500-5000 \mathrm{~K}$ [28], it is impossible to take the samples in situ or monitor the process of reactions during arc discharge with any present technique, so there is little direct experimental evidence for the mechanisms of formation of graphene and carbon nanotubes [29]. By analyzing the results of EELS line scanning measurement in detail, however, it may be possible to get helpful information or indirect evidence for one to understand the mechanism of formation of the asprepared core-shell nanoparticles, like the investigation on fossil. As far as we know, no such analyzing work has been reported until now.

Figure 4(a) shows the image of the morphology corresponding to the EELS line scanning measurement of nanoparticle A in Figure 3(b). It is shown in Figure 4(b) that, in the region of the upper shell (3.7-9.7 nm), along the radial direction of nanoparticle A, C signal gradually increases to the maximum and then reduces gradually; Fe signal gradually reduces to zero; $\mathrm{O}$ signal gradually increases to a maximum and then gradually decreases to zero; $\mathrm{N}$ signal is very weak. In the region of the lower shell (87.5-94.2 nm), also along the radial direction of nanoparticle $\mathrm{A}$, the $\mathrm{C}, \mathrm{Fe}, \mathrm{O}$, and $\mathrm{N}$ signals show the similar changes as those observed in the region of the upper shell. The above results indicate that the elemental compositions in the upper and lower shells are not uniform and the trends of their changes are basically the same.

It is also shown in Figure 4(b) that in the core region (9.7$87.5 \mathrm{~nm}$ ) of nanoparticle A, C signal is gradually weakened in the region of $9.7-20 \mathrm{~nm}$ at first and then slightly remains unchanged; it gradually increases in the region of $83-87.5 \mathrm{~nm}$; that is, it gradually increases on both sides of the center, along the radial direction of nanoparticle $\mathrm{A}$; Fe signal gradually increases in the region of 9.7-14 $\mathrm{nm}$ and gradually decreases in the region of $82-87.5 \mathrm{~nm}$; that is, there is a slight concave on the curve between 14 and $82 \mathrm{~nm}$. The slight concave may be caused by the comparatively large diameter of nanoparticle $\mathrm{A}$, as the electron beam of EELS line scanning measurement could not penetrate it completely, leading to the decrease of $\mathrm{Fe}$ signal collected; the maximum of $\mathrm{O}$ signal appears in both the upper and lower shells, near the position of interface between shell and core, and it gradually increases in both regions of $9.7-20 \mathrm{~nm}$ and $80-87.5 \mathrm{~nm}$ along the radial direction of nanoparticle A but is very weak in the region 20$80 \mathrm{~nm}$, though there are some fluctuations; N signal is very weak almost in the whole region. The above results indicate that the elemental compositions of two regions with lengths of about $10 \mathrm{~nm}$ at the inner sides of the interfaces between shell and core are nonuniform and the composition of the central region $(20-80 \mathrm{~nm})$ of the core is relatively uniform. Based on the above results of HRTEM, EDX, and EELS line scanning characterizations, it can be concluded that the nanoparticles in product $\mathrm{B}$, with core-shell structure, are $\mathrm{N}$ doped CSEINPs.

Figure 4(c) is the magnified image of the morphology of nanoparticle A corresponding to EELS line scanning measurement. In order to further investigate the uniformity of composition of nanoparticle A, seven representative points are selected along the track of the EELS line scanning measurement. $\mathrm{P}_{1}$ and $\mathrm{P}_{7}$ points are located at the midpoints of the upper and lower shells, respectively, $\mathrm{P}_{2}$ and $\mathrm{P}_{6}$ points are located at the inner sides of the interfaces between shell and core, $\mathrm{P}_{3}$ and $\mathrm{P}_{5}$ are located at the midpoints of the core radius, and $\mathrm{P}_{4}$ is the center of the core.

Figure 4(d) shows the EELS spectra corresponding to $\mathrm{P}_{1}-$ $\mathrm{P}_{7}$ points, respectively. For the characteristic peaks of the C-K edge ( 287-297 eV), the peak intensities of the spectra at $\mathrm{P}_{1}$ and $\mathrm{P}_{7}$ points are remarkably stronger than those at other five points, but the peak intensity at $\mathrm{P}_{1}$ is obviously stronger than that at $\mathrm{P}_{7}$ point; the peak intensities at $\mathrm{P}_{2}$ and $\mathrm{P}_{6}$ points take second place and the difference between them is not obvious; the peak intensities at $\mathrm{P}_{3}, \mathrm{P}_{4}$, and $\mathrm{P}_{5}$ points are the weakest and the difference among them is also not obvious. For the characteristic peaks of the N-K edge ( 398$415 \mathrm{eV})$, all the peak intensities at $\mathrm{P}_{1}-\mathrm{P}_{7}$ points are very weak. For the characteristic peaks of the $\mathrm{O}-\mathrm{K}$ edge $(\sim 530-560 \mathrm{eV})$, there are obviously weak peaks at $\mathrm{P}_{2}$ and $\mathrm{P}_{6}$ points and no 


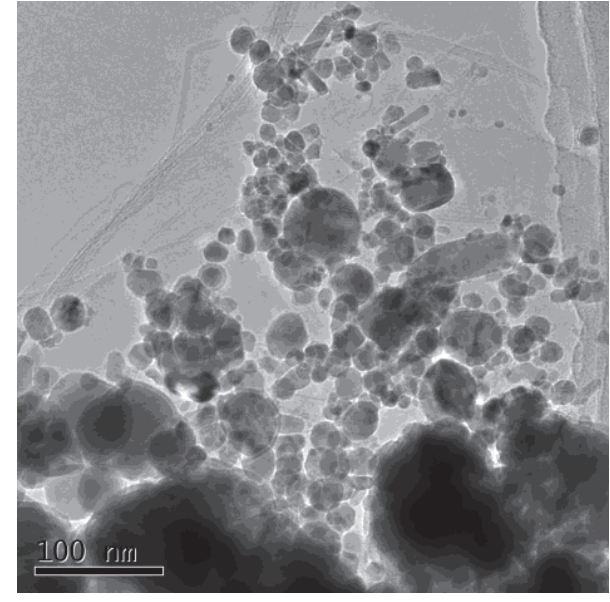

(a)

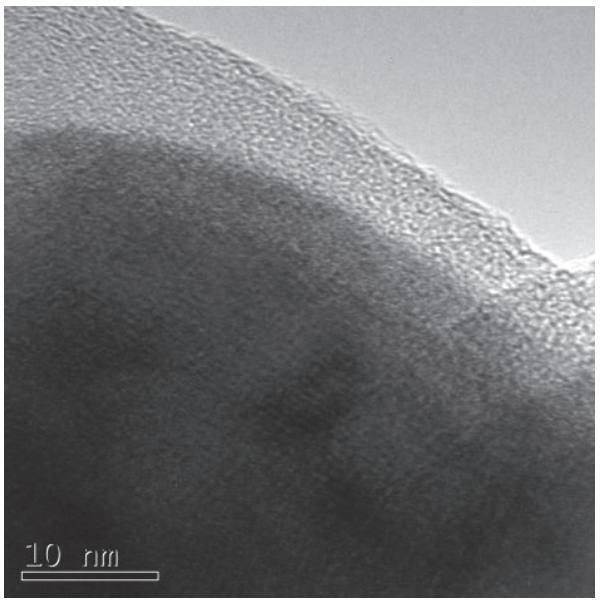

(c)

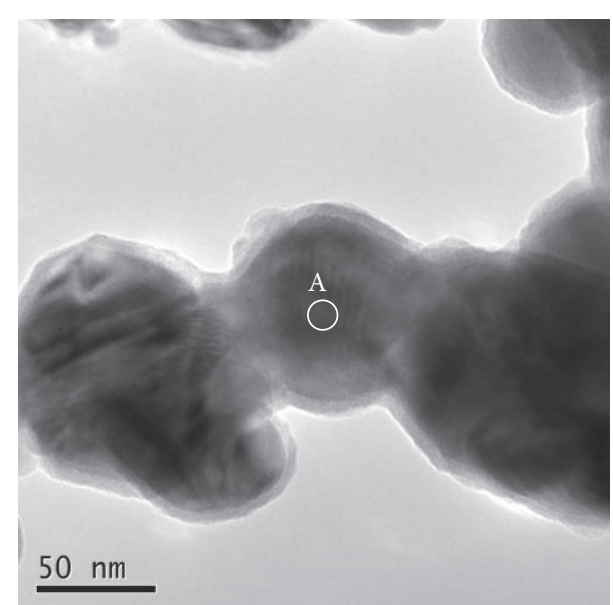

(b)

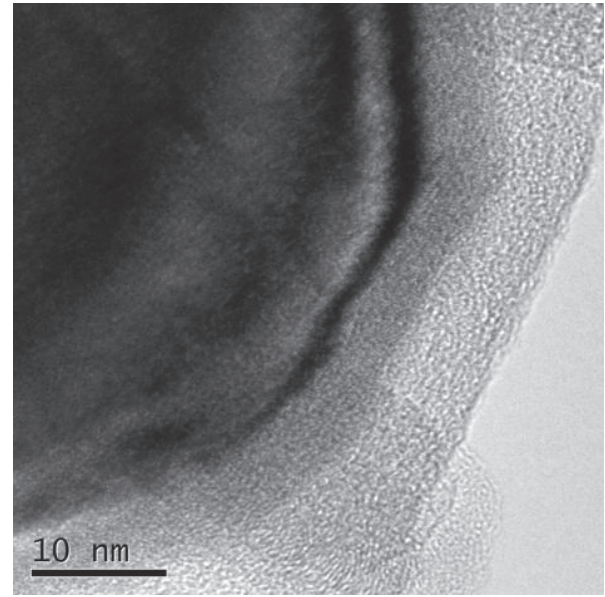

(d)

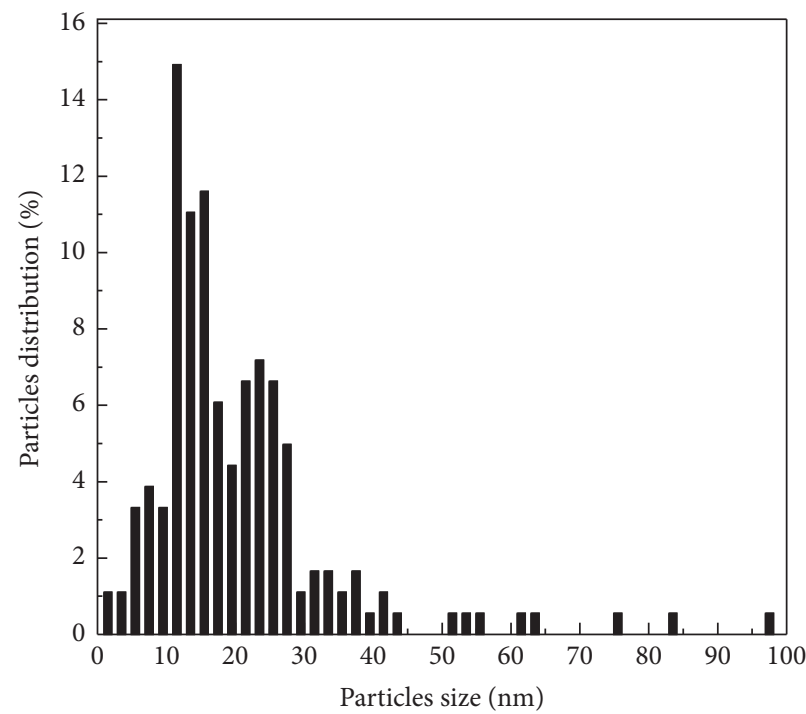

(e)

Figure 3: (a) HRTEM image of product B at low magnification. (b) Several nanoparticles with core-shell structure; (c) and (d) high magnification of the upper and lower shells of nanoparticle A in (b). (e) Histogram of size distribution of the nanoparticles. 


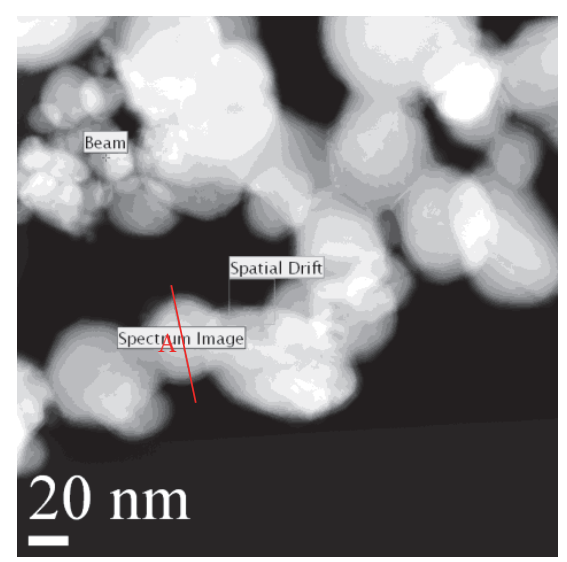

(a)

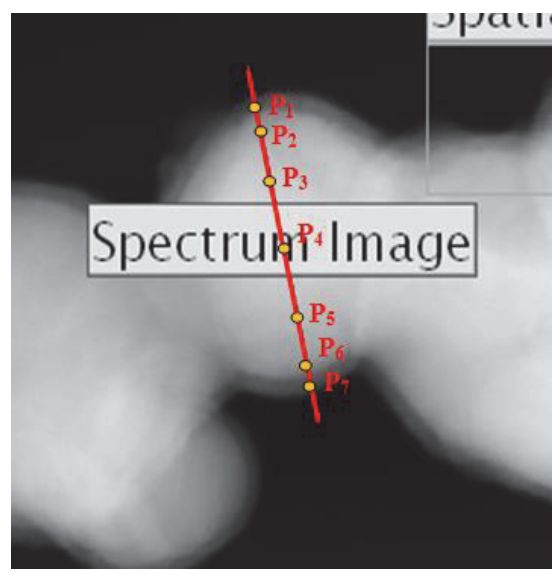

(c)

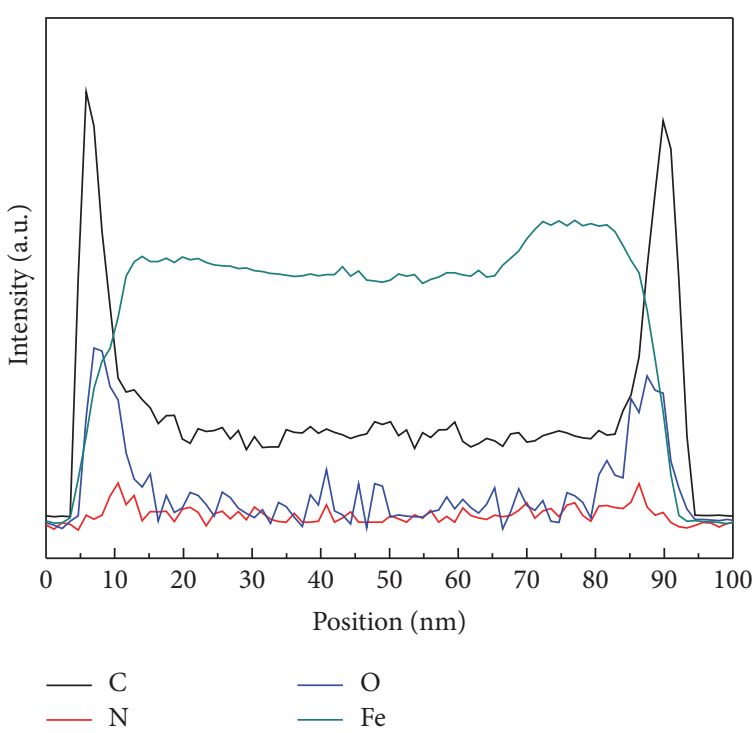

(b)

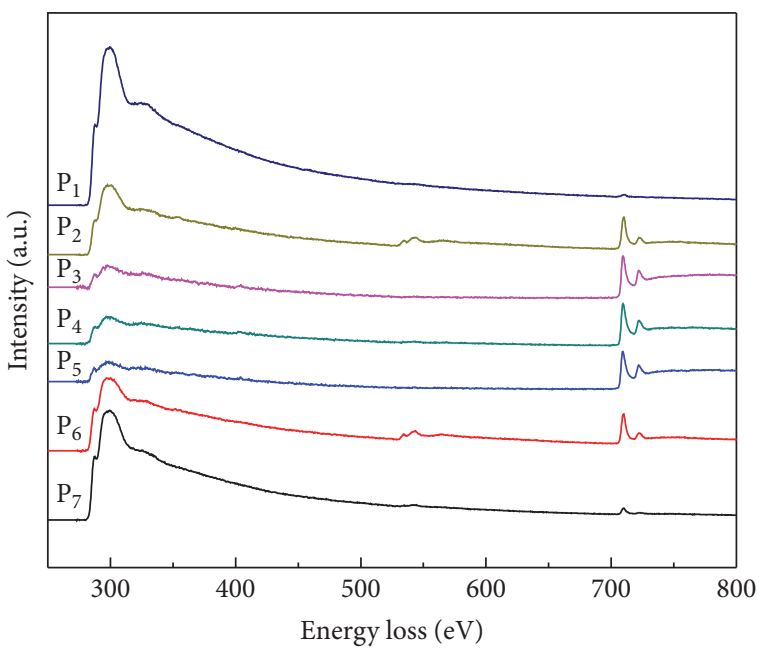

(d)

FIGURE 4: (a) Image of the morphology corresponding to EELS line scanning measurement of nanoparticle A and (b) EELS line scanning spectra of nanoparticle A. (c) Magnified image of the morphology of nanoparticle A and (d) EELS spectra corresponding to $P_{1}-P_{7}$ points in (c), respectively.

obvious peaks at other five points. For the characteristic peaks of the Fe-L edge $(\sim 709-722 \mathrm{eV})$, the peak intensities at $\mathrm{P}_{1}$ and $\mathrm{P}_{7}$ points are very weak and those at other five points are comparatively strong, but the peak intensities at $\mathrm{P}_{3}, \mathrm{P}_{4}$, and $\mathrm{P}_{5}$ points are slightly stronger than those at $\mathrm{P}_{2}$ and $\mathrm{P}_{6}$ points. It is known from the above analysis that the EELS spectra at the points of the symmetrical positions are similar, except those at $\mathrm{P}_{1}$ and $\mathrm{P}_{7}$ points, but those at the different points of the asymmetrical ones show remarkably different peak intensities.

Figures $5(a)-5(d)$ show the fine structures of C-K, N-K, $\mathrm{O}-\mathrm{K}$, and $\mathrm{Fe}-\mathrm{L}$ edges in the EELS spectra of $\mathrm{P}_{1}-\mathrm{P}_{4}$ points, respectively. The peak intensities $(287.9 \mathrm{eV}$ and $297.4 \mathrm{eV})$ at $\mathrm{P}_{1}$ and $\mathrm{P}_{2}$ points are stronger than those at $\mathrm{P}_{3}$ and $\mathrm{P}_{4}$ points, as shown in Figure 5(a). These peaks reveal that the $\mathrm{sp}^{2}$ hybridization of carbon atoms is present in the nanoparticle and the peak at $287.9 \mathrm{eV}$ can be attributed to the electron transition of excitation from Cls core level to $\pi^{*}$ band, and the sharper this peak is, the higher the degree of graphitization of the corresponding structure is; the broadband at $\sim 297.4 \mathrm{eV}$ is the characteristic peak of the electron transition of excitation from C1s level to $\sigma^{*}$ band [29].

Figure 5(b) shows that, at $\mathrm{P}_{1}$ point, there are three peaks at ca. $398.3 \mathrm{eV}, 399.3 \mathrm{eV}$, and $401.6 \mathrm{eV}$, but the peak at $399.3 \mathrm{eV}$ is very weak; at $\mathrm{P}_{2}$ point, there are three peaks at $398.3 \mathrm{eV}$, $399.8 \mathrm{eV}$, and $401.8 \mathrm{eV}$, but the peak at $399.8 \mathrm{eV}$ is stronger than the other two ones; at $\mathrm{P}_{3}$ point, there are two peaks at $398.3 \mathrm{eV}$ and $401.6 \mathrm{eV}$; at $\mathrm{P}_{4}$ point, there are two peaks at $398.3 \mathrm{eV}$ and $401.9 \mathrm{eV}$, but the latter is stronger than the former. The peaks at $398.3 \mathrm{eV}, 399.8 \mathrm{eV}$, and $401.8 \mathrm{eV}$ should 


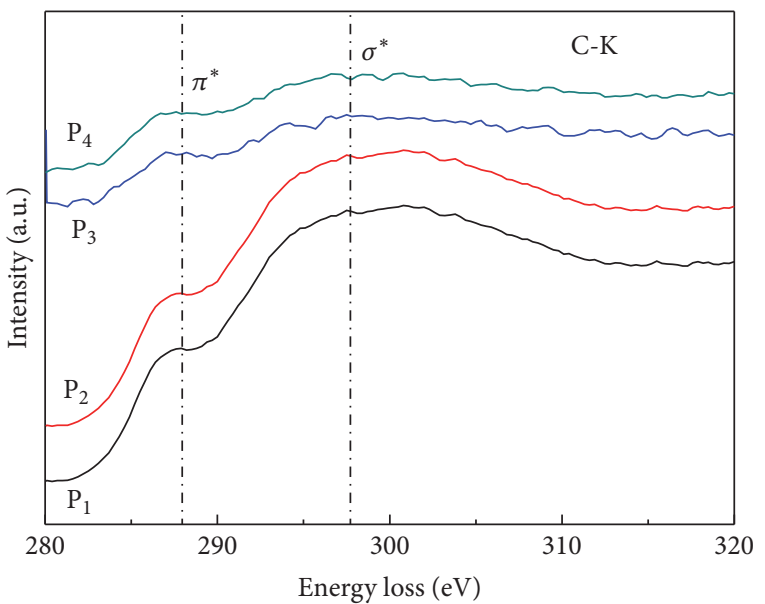

(a)

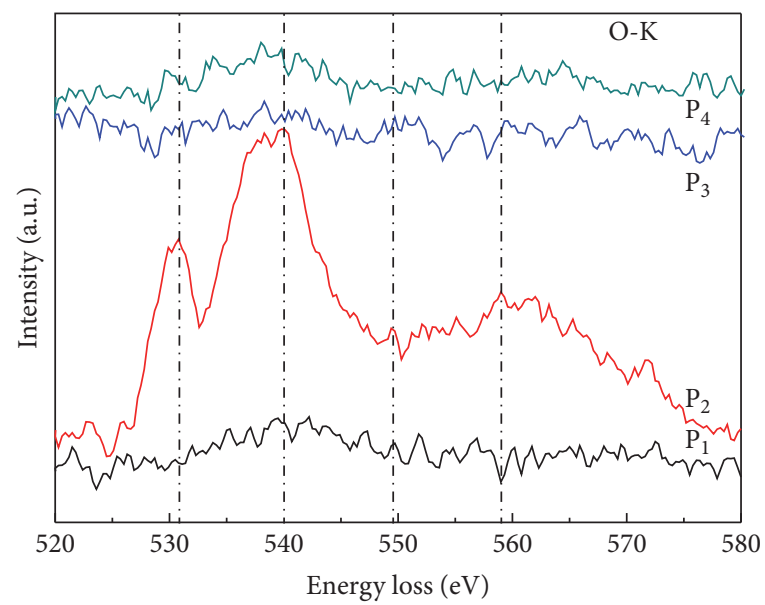

(c)

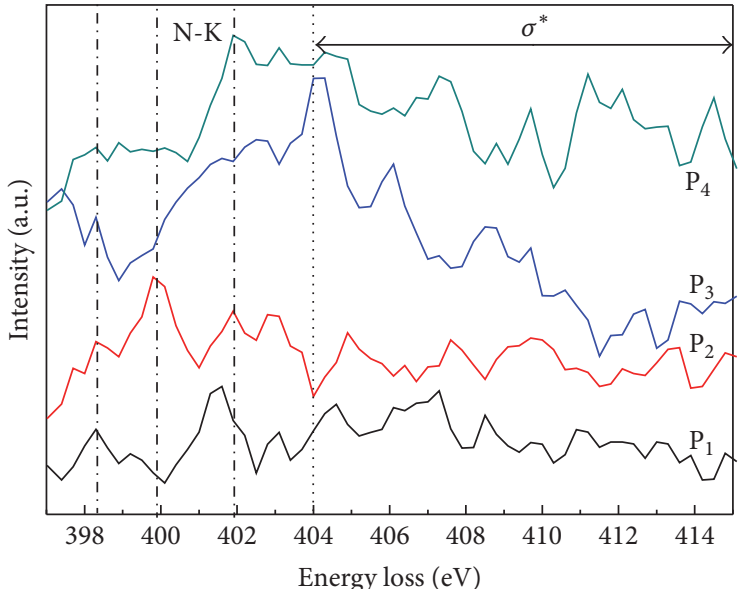

(b)

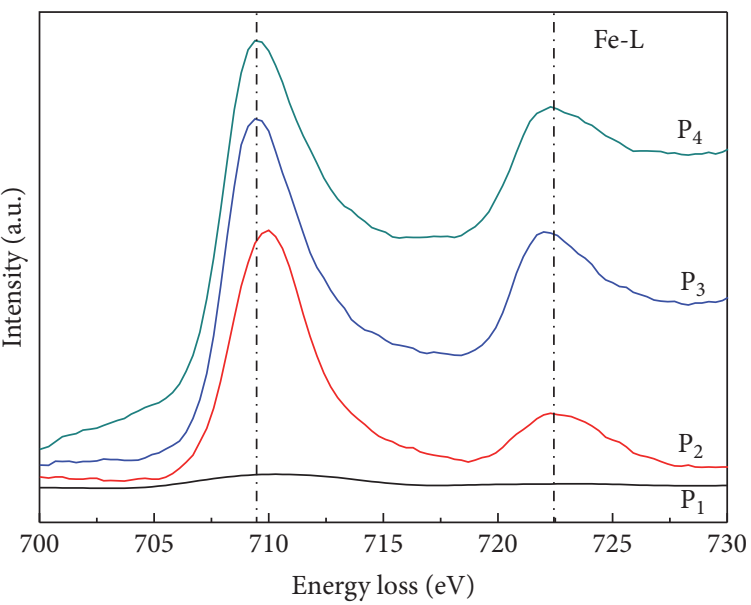

(d)

Figure 5: Fine structures of C-K (a), N-K (b), O-K (c), and Fe-L (d) edges in the EELS spectra of $\mathrm{P}_{1}-\mathrm{P}_{4}$ points.

correspond to the $\pi^{*}$ characteristic peaks of the pyridinic, pyrrolinic, and graphitic nitrogen, respectively [30]. The peaks between 404 and $415 \mathrm{eV}$ belong to the $\sigma^{*}$ characteristic band of N-K edge [31]. The differences among the peak intensities and positions at the different points mean that the mechanisms of nitrogen taking part in the reactions during the process of formation of the nanoparticle may be different.

Figure 5(c) shows that the characteristic peaks of O-K edge are weak at $\mathrm{P}_{1}, \mathrm{P}_{3}$, and $\mathrm{P}_{4}$ points, but those at $\mathrm{P}_{2}$ point are strong, especially the two peaks at $530.8 \mathrm{eV}$ and $540.0 \mathrm{eV}$. The peak at $530.8 \mathrm{eV}$ corresponds to the electron transition from O1s core state to the unoccupied orbitals formed by the interaction of the $\mathrm{O} 2 \mathrm{p}$ with the Fe3d states; the other three peaks at $540.0 \mathrm{eV}, 549.6 \mathrm{eV}$, and $558.9 \mathrm{eV}$ are generally attributed to the electron transition from the Ols to the vacant orbitals formed by the interaction of the $\mathrm{O} 2 \mathrm{p}$ with the Fe4s and $4 \mathrm{p}$ states $[32,33]$. The remarkable difference between the peak intensity at $\mathrm{P}_{2}$ and those at $\mathrm{P}_{1}, \mathrm{P}_{3}$, and $\mathrm{P}_{4}$ means that the main range of temperature of oxygen taking part in the reactions during the process of formation of the nanoparticle may be limited.
Figure 5(d) shows that the characteristic peaks of Fe$\mathrm{L}$ edge are very weak at $\mathrm{P}_{1}$ point, but the characteristic peaks of $\mathrm{L}_{3}(709.4 \mathrm{eV})$ and $\mathrm{L}_{2}(722.4 \mathrm{eV})$ edges at $\mathrm{P}_{2}-\mathrm{P}_{4}$ points are obviously strong and their intensities gradually increase from $\mathrm{P}_{2}$ to $\mathrm{P}_{4}$ points. These two peaks should correspond to the electron transitions from the two levels, formed due to the spin-orbital splitting of $2 \mathrm{p}$ orbitals, to the $3 d$ ones $\left(2 p_{3 / 2} \rightarrow 3 d\right.$ and $\left.2 p_{1 / 2} \rightarrow 3 d\right)$, respectively $[32,34]$. The remarkable difference between the peak intensities at $\mathrm{P}_{2}-\mathrm{P}_{4}$ and that at $\mathrm{P}_{1}$ means that the degree of iron taking part in the reactions should gradually decrease from the center of core to the interface between core and shell and then sharply declines during the formation of shell.

The above analysis shows that there are some differences among the bonding states between the distinct elements at the different points of the nanoparticle $\mathrm{A}$, concerning the mechanism, degree, and temperature range of the different elements taking part in the reactions during the process of arc discharge. Such information should be a kind of true reflection for the mechanism of formation of the as-prepared core-shell nanoparticles, like the information found in fossil, 


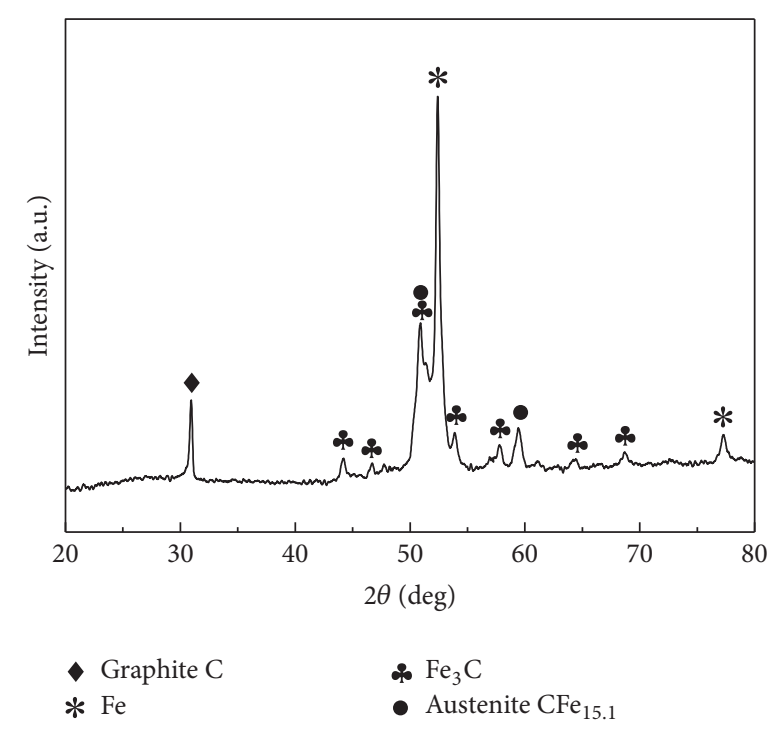

FIGURE 6: XRD pattern of the product B (Co K $\alpha)$.

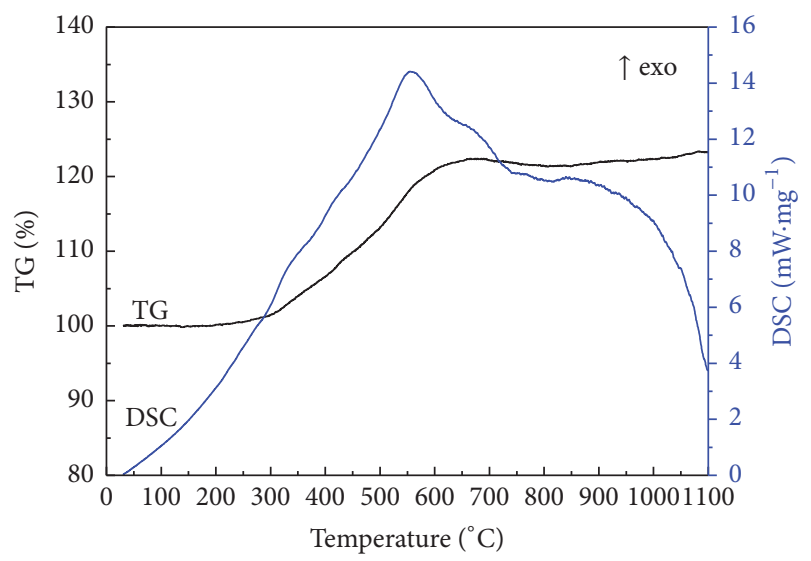

FIGURE 7: TG-DSC curves of product B.

by which one can guess what may happen or exist in the ancient time.

Figure 6 shows the XRD pattern of products B. The diffraction peak at $30.96^{\circ}$ is matched well with graphite carbon (PDF Card Number 75-2078). The peaks at $44.19^{\circ}$, $46.74^{\circ} 50.96^{\circ}, 53.94^{\circ}, 57.86^{\circ}, 61.26^{\circ}, 64.47^{\circ}$, and $68.68^{\circ}$ can be ascribed to $\mathrm{Fe}_{3} \mathrm{C}$ (PDF Card Number 72-1110); those at $52.40^{\circ}$ and $77.41^{\circ}$ can be assigned to Fe (PDF Card Number 870721); those at $50.968^{\circ}$ and $59.47^{\circ}$ can be attributed to $\mathrm{CFe}_{15.1^{-}}$ Austenite (PDF Card Number 52-0512). The above results reveal that the phase composition of products $\mathrm{B}$ includes graphitic carbon, $\mathrm{Fe}, \mathrm{Fe}_{3} \mathrm{C}$, and Austenite $\mathrm{CFe}_{15.1}$. The XRD patterns of the products A, D, and E (see Figure S5 in Supplementary Material) show the similar profile with that in Figure 6; that is, they have the similar phase composition with the product $\mathrm{B}$.

Figure 7 shows the TG-DSC curves of the products $\mathrm{B}$. The TG curve shows that from room temperature to about $220^{\circ} \mathrm{C}$ the sample did not have obvious weight change; from $220^{\circ} \mathrm{C}$ to $675^{\circ} \mathrm{C}$, it had a remarkable weight gain; from $675^{\circ} \mathrm{C}$ to $1100^{\circ} \mathrm{C}$, it had only a small weight gain. The DSC curve shows

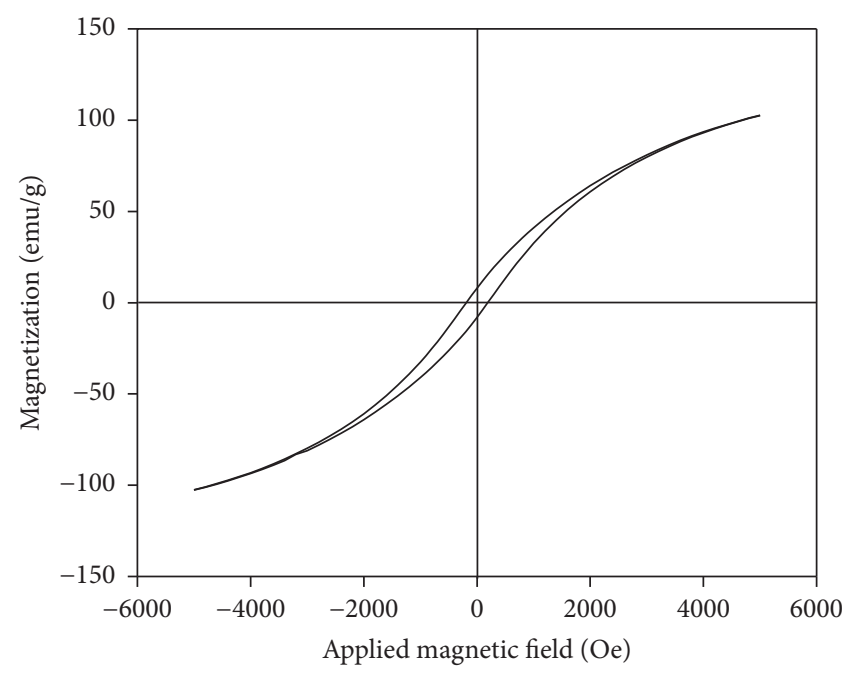

FIGURE 8: Magnetic hysteresis loop of product B at room temperature.

one strong and two weak exothermic peaks. The strong peak that appeared at $556^{\circ} \mathrm{C}$ is due to the oxidation of amorphous carbon and iron species [35], and the weak peaks which appeared at $656^{\circ} \mathrm{C}$ and $840^{\circ} \mathrm{C}$ are due to the oxidation of graphite carbon and the deep oxidation of little iron species $[36,37]$, respectively. As the sample had finally weight gain, it is inferred that the weight gain of oxidation of iron species is larger than the weight loss of oxidation of graphite carbon. The $\mathrm{Fe}$ content of product $\mathrm{B}$ was calculated to be about 85.6 wt.\%, supposing that the final sample (residue) is $\mathrm{Fe}_{2} \mathrm{O}_{3}$ [38]. The TG-DSC curves of the products A, D, and E (see Figure S6 in Supplementary Material) are somewhat different from those in Figure 7, but the Fe contents in A and E are 85.4 wt. $\%$ and $85.7 \mathrm{wt} . \%$, respectively, very close to that in product $\mathrm{B}$, and the Fe content in D is a bit low (80.4 wt.\%). This means that there may be some difference among the microstructures of the products $\mathrm{A}, \mathrm{B}, \mathrm{D}$, and $\mathrm{E}$.

The magnetic hysteresis loop (MHL) of the product $\mathrm{B}$, measured at room temperature, demonstrates the ferromagnetic behavior, as shown in Figure 8 . The $M s$ value of product $\mathrm{B}$ is $130 \mathrm{emu} / \mathrm{g}$, estimated from the full MHL of product B (see Figure S7 in Supplementary Material), which is much larger than that of product $\mathrm{B}_{\mathrm{II}}(M s=89 \mathrm{emu} / \mathrm{g})$ [39]. The main reason may be that the shells of these two kinds of core-shell nanoparticles consist of different compositions and structures, as the Fe content of B is only slightly larger than that of $\mathrm{B}_{\mathrm{II}}$ (Table 1). The shells of the nanoparticles in $\mathrm{B}_{\mathrm{II}}$ consist of three to seven layers of graphite and graphite is diamagnetic material, leading to the decrease of $M s$ value [40]. The shells of the nanoparticles in $\mathrm{B}$ are the composite one containing $\mathrm{C}, \mathrm{Fe}, \mathrm{O}$, and $\mathrm{N}$ elements, and $\mathrm{Fe}_{3} \mathrm{C}$ is the weakly ferromagnetic phase $(M s=\sim 140 \mathrm{emu} / \mathrm{g}$ [39] $), \mathrm{Fe}_{3} \mathrm{~N}$ is the ferromagnetic phase [41], austenite is the paramagnetic phase $[42,43]$, and iron oxide is the superparamagnetic phase, leading to the larger $M s$ value [44]. But both the two $M s$ values are smaller than that of the bulk iron $(M s=$ $222 \mathrm{emu} / \mathrm{g}$ ) [39]. This is because both $\mathrm{B}$ and $\mathrm{B}_{\mathrm{II}}$ are mainly composed of the nanoparticles with core-shell structure. 
TABLE 1: Fe contents, shell structures, and magnetic properties of the products $B$ and $B_{I I}$.

\begin{tabular}{lccccccc}
\hline Sample & Fe content (wt.\%) & Av. particle size $(\mathrm{nm})$ & Shell structure & $M s(\mathrm{emu} / \mathrm{g})$ & $H c(\mathrm{Oe})$ & $M r / M s$ & Reference \\
\hline $\mathrm{B}$ & 85.6 & 20.8 & Composite shell & 130 & 194 & 0.062 & This work \\
$\mathrm{B}_{\mathrm{II}}$ & 82.6 & 20.6 & 3-7 layers of graphite & 89 & 240 & 0.124 & {$[39]$} \\
\hline
\end{tabular}

The $H c$ value of product $\mathrm{B}$ is $194 \mathrm{Oe}$, which is smaller than that of $\mathrm{B}_{\mathrm{II}}(240 \mathrm{Oe})$ [39] (both of the $\mathrm{Hc}$ values are much larger than that of the bulk iron $(H c=\sim 1 \mathrm{Oe})[45])$. The reason may be the same as the above one for the difference between two $M s$ values, as the difference between the average sizes of the nanoparticles of $\mathrm{B}$ and $\mathrm{B}_{\mathrm{II}}$ is not large. The magnetic properties of the material can also be characterized by the ratio of remanent magnetization to saturation one $(\mathrm{Mr} / \mathrm{Ms})$. When the ratio is less than 0.25 or the particle sizes of the materials are smaller than the value of their magnetic single domain (about $20 \mathrm{~nm}$ for Fe and $60 \mathrm{~nm}$ for $\mathrm{Fe}_{3} \mathrm{C}$ ) [46, 47], the materials will show superparamagnetism at room temperature [46]. Although the $M r / M s$ value (0.062) of B is much smaller than 0.25 , it shows ferromagnetic behavior. This may be because the sizes of about $39.2 \%$ nanoparticles of the product $\mathrm{B}$ are larger than $20 \mathrm{~nm}$ (Figure 3(e)).

Figure 9(a) shows the removal efficiency of MB solution $\left(C_{0}=10 \mathrm{mg} / \mathrm{L}\right)$ with the $\mathrm{N}$-doped CSEINPs under natural light. It can be observed that the $\mathrm{MB}$ adsorption on the $\mathrm{N}$ doped CSEINPs is very fast at the first $3 \mathrm{~min}$ and it almost reaches the adsorption equilibrium in $10 \mathrm{~min}$. The insets in Figure 9(a) show the color change of the MB solution before (left) and after (right) being treated with the N-doped CSEINPs. Figure 9(b) shows that the adsorption capacity of $\mathrm{MB}$ increases from 19.9 to $44.3 \mathrm{mg} / \mathrm{g}$ in $300 \mathrm{~min}$, with the increase of the $C_{0}$ from 10 to $60 \mathrm{mg} / \mathrm{L}$. The inset in Figure 9(b) shows that the MB adsorption on the N-doped CSEINPs is also very fast at the first $3 \mathrm{~min}$ for all of the MB solutions and the adsorption amount of $\mathrm{MB}$ obviously increases with the increase of the $C_{0}$, neglecting the experimental error. The results may be attributed to an increase in the driving force of concentration gradient with the increase of the $C_{0}$.

The kinetic data were analyzed using pseudo-secondorder kinetics, which was defined as follows [18]:

$$
\frac{t}{q_{t}}=\frac{t}{q_{e}}+\frac{1}{k_{2} q_{e}^{2}}
$$

where $q_{t}$ and $q_{e}$ are the adsorption amounts of $\mathrm{MB}$ at the time $t$ and equilibrium ( $\mathrm{mg} / \mathrm{g}$ ), respectively. $k_{2}$ is the pseudosecond-order rate constant of the kinetic model (g/mg-min).

Figure 9 (c) shows the kinetic curves of $t / q_{t}$ against $t$ and the values of kinetic parameters are listed in Table 2. It is observed from Figure 9(c) that the slope of the curve decreases with the increase of $C_{0}$. The correlation coefficients $R_{2}$ in Table 2 are higher than 0.99 and the experimental value $q_{e}\left(q_{e \text {-exp }}\right)$ is in accordance with the calculated one $q_{e}\left(q_{e-\mathrm{cal}}\right)$. This means that the adsorption of $\mathrm{MB}$ on the $\mathrm{N}$ doped CSEINPs fits the pseudo-second-order kinetic model $[22,27,48]$.

The above adsorption performance of the $\mathrm{N}$-doped CSEINPs may be ascribed to the defects and dangling bonds on the surfaces of them, as they formed under the conditions of large temperature and concentration gradients. In addition, as aqueous $\mathrm{MB}$ is a cationic monovalent dye [49], the electrostatic interactions between the positively charged dye and oxygen-containing functional groups on the surface of $\mathrm{N}$-doped CSEINPs also play an important role in the adsorption [50].

Figure 10(a) shows the curves of the removal rate of $\mathrm{MB}$ $\left(C_{0}=10 \mathrm{mg} / \mathrm{L}\right)$, without and with the N-doped CSEINPs. In the blank experiment, the concentration of $\mathrm{MB}$ shows no change, with no IVL. The concentration of MB gradually decreases with the extension of IVL (the decrement is ca. $13 \%$ in $150 \mathrm{~min}$ ). This may mean that $\mathrm{MB}$ has a little photolysis under IVL [50]. The adsorption equilibrium was reached in $10 \mathrm{~min}$ in the dark and the corresponding removal rate of $\mathrm{MB}$ was ca. $66 \%$, in presence of the $\mathrm{N}$-doped CSEINPs. The removal rate of $\mathrm{MB}$ gradually increased with the extension of IVL and reached about $90 \%$ in $150 \mathrm{~min}$. Figure 10(b) shows the adsorption spectra of $\mathrm{MB}$ solution at different adsorption and IVL time with the N-doped CSEINPs. The intensity of the characteristic absorption peak of $\mathrm{MB}$ at $664 \mathrm{~nm}$ decreased sharply at 10 min after the $\mathrm{N}$-doped CSEINPs were added and then gradually decreased with the extension of IVL.

To evaluate the reusability of the N-doped CSEINPs, the recycling test for the adsorption and photocatalytic degradation of MB with the N-doped CSEINPs was carried out, and the results are shown in Figure 11. After the first cycle, the abilities of the adsorption and photocatalytic degradation decrease obviously, and then they gradually decrease with the increase of the number of cycles. In the fourth cycle, only about $50 \%$ of $\mathrm{MB}$ can be removed with the $\mathrm{N}$-doped CSEINPs. The reasons for the above results may be that some residual MB molecules adsorbed on the N-doped CSEINPs hindered the adsorption and reduced the active sites.

Figure 12(a) shows the FTIR spectrum of the N-doped CSEINPs. The strong broad peak at $\sim 3442 \mathrm{~cm}^{-1}$ is attributed to stretching vibration of hydroxyl groups (-OH groups) of adsorbed water. The weak peaks at $\sim 2921 \mathrm{~cm}^{-1}$ and $1391 \mathrm{~cm}^{-1}$ are associated with stretching vibration and flexural vibration of C-H bonds, respectively. The peak at $\sim 1627 \mathrm{~cm}^{-1}$ is related to $\mathrm{C}=\mathrm{O}$ group. The peaks at $\sim 1116$ and $1044 \mathrm{~cm}^{-1}$ are ascribed to $-\mathrm{C}-\mathrm{OH}$ groups. The peak at $\sim 598 \mathrm{~cm}^{-1}$ is characteristic of the Fe-O vibrations [27]. Those hydrophilic functional groups result in the enhanced hydrophilia of the obtained composite. Figure 12(b) shows the FTIR spectrum of the Ndoped CSEINPs-MB complex. The latter is obviously different from the former; that is, some peaks in the former sharply decrease or almost disappear, and the characteristic peaks of MB molecules appear, shifting to the lower wavenumbers (ca. 1581 and $1326 \mathrm{~cm}^{-1}$ ) [51]. The changes in FTIR spectra indicate that ionic interactions between cationic dyes and the 


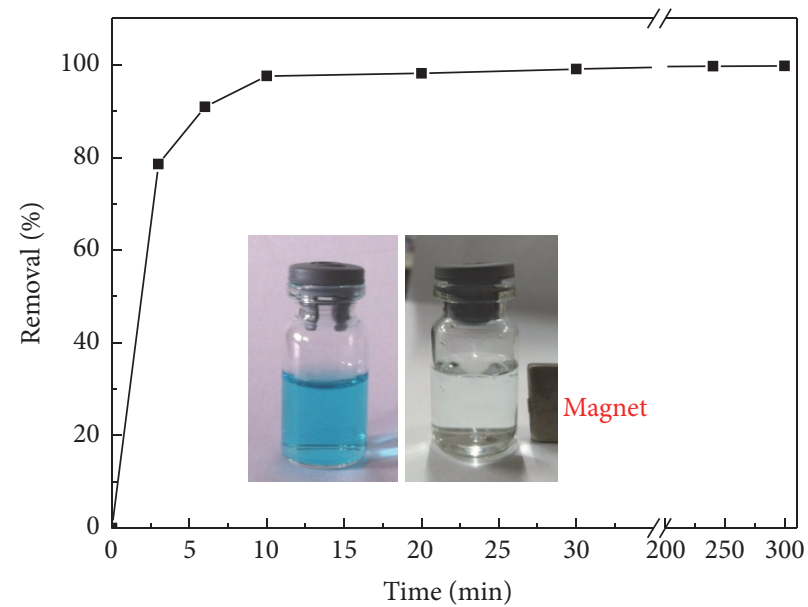

(a)

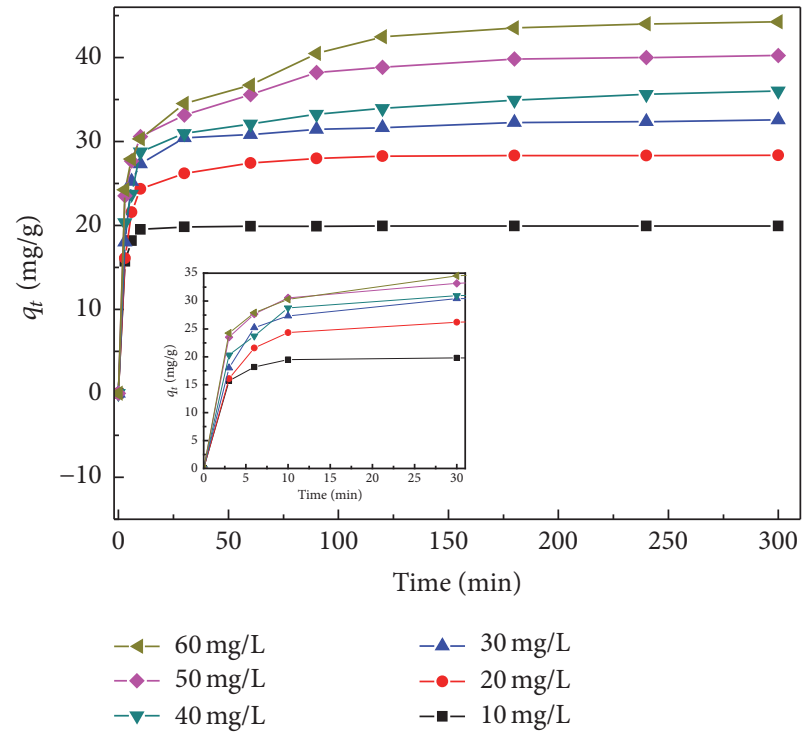

(b)

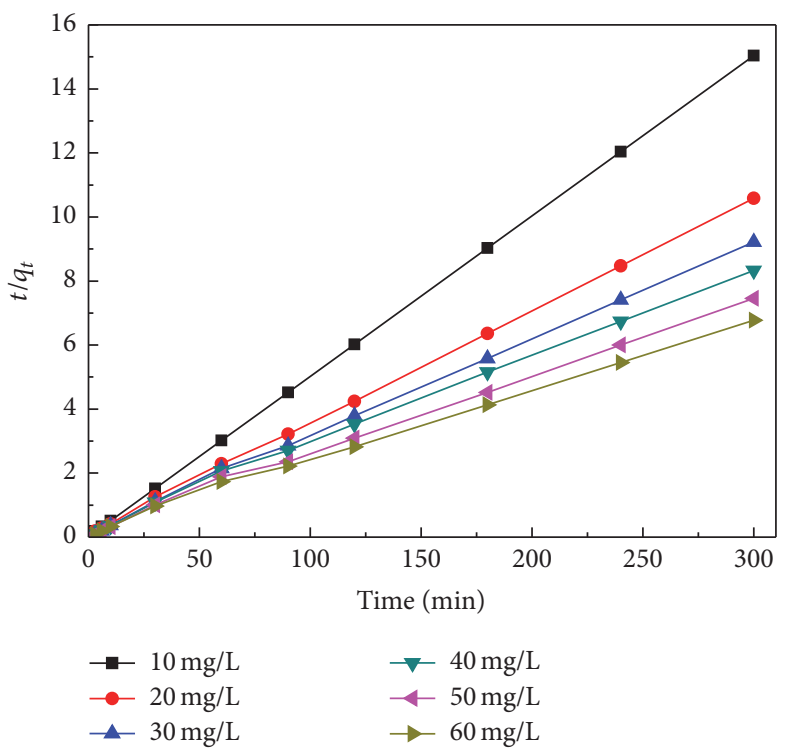

(c)

FIgure 9: (a) The removal efficiency of $\mathrm{MB}\left(C_{0}=10 \mathrm{mg} / \mathrm{L}\right)$ with the $\mathrm{N}$-doped CSEINPs versus time; the insets show the photographs of the MB aqueous solution before (left) and after (right) being treated with the N-doped CSEINPs. (b) Curve of the adsorbed amount of MB with the N-doped CSEINPs versus time $\left(C_{0}=10-60 \mathrm{mg} / \mathrm{L}\right)$. (c) Kinetics curves of adsorption of MB on the N-doped CSEINPs.

TABLE 2: Parameters of pseudo-second-order kinetic model of MB adsorbed by the N-doped CSEINPs.

\begin{tabular}{|c|c|c|c|c|}
\hline Concent. ratio $(\mathrm{mg} / \mathrm{L})$ & $q_{e-\exp }(\mathrm{mg} / \mathrm{g})$ & $q_{e-\mathrm{cal}}(\mathrm{mg} / \mathrm{g})$ & $k_{2}(\mathrm{~g} / \mathrm{mg} \cdot \mathrm{min})$ & $R_{2}$ \\
\hline 10 & 19.95 & 19.98 & $1.18 \times 10^{-1}$ & 0.999 \\
\hline 20 & 28.35 & 28.69 & $1.14 \times 10^{-2}$ & 0.999 \\
\hline 30 & 32.56 & 32.84 & $8.08 \times 10^{-3}$ & 0.999 \\
\hline 40 & 36.02 & 36.38 & $4.42 \times 10^{-3}$ & 0.998 \\
\hline 50 & 40.25 & 40.93 & $3.93 \times 10^{-3}$ & 0.998 \\
\hline 60 & 44.27 & 45.20 & $2.81 \times 10^{-3}$ & 0.997 \\
\hline
\end{tabular}




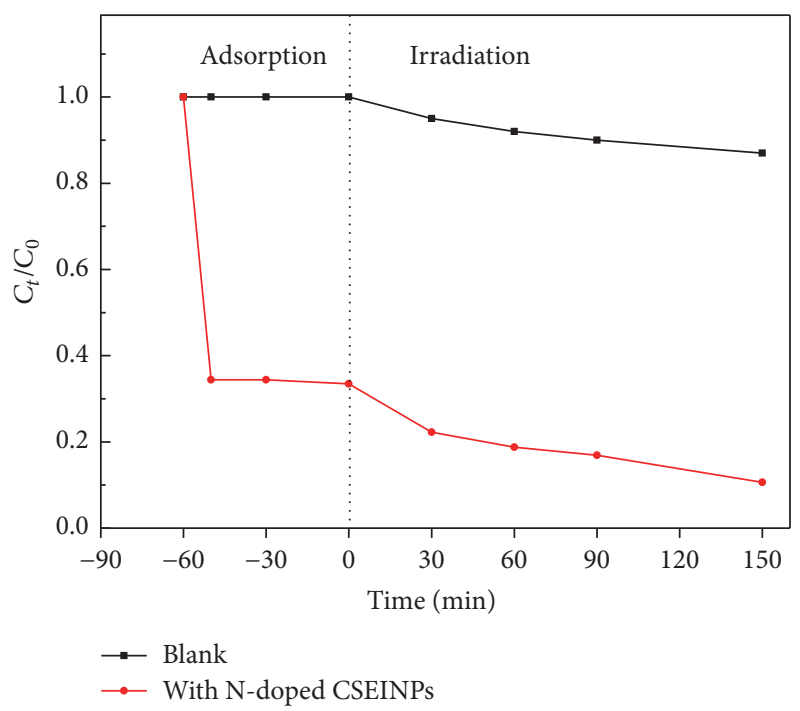

(a)

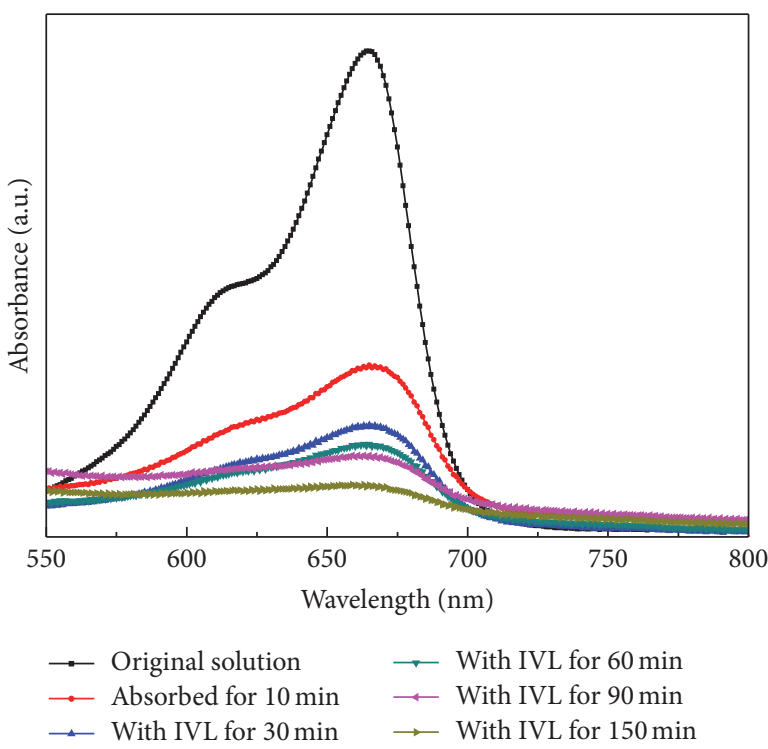

(b)

FIgURE 10: (a) Curves of the removal rate of MB versus time, without (blank) and with the N-doped CSEINPs, in the dark and then under IVL. (b) Changes of the UV-vis spectra of the MB aqueous solution versus time, without and under IVL, in presence of the N-doped CSEINPs.

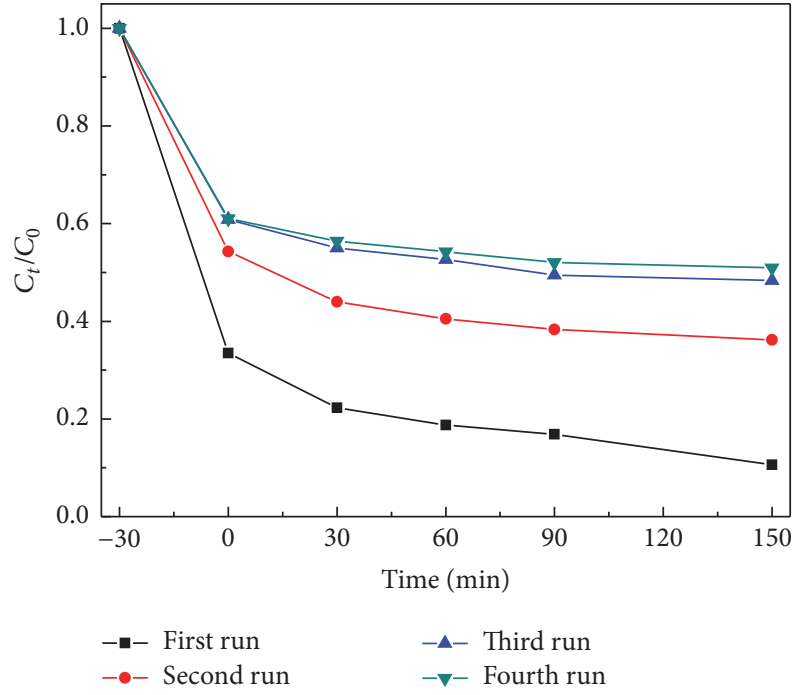

FIGURE 11: Recycling test for the photocatalytic degradation of MB with the N-doped CSEINPs.

negatively charged groups were formed and $\mathrm{MB}$ molecules were adsorbed on the surfaces of the N-doped CSEINPs.

Figure 13 shows the HRTEM images of the N-doped CSEINPs after being used in the recycling test. Compared with Figures 3(a) and 3(b), it is found that the morphology and structure of the nanoparticles have changed significantly; that is, many of the nanoparticles are already not approximately spherical and do not have the core-shell structure, and the dispersion of the nanoparticles becomes bad. The result of EDX measurement shows that the atomic percent contents of the elements $\mathrm{C}, \mathrm{Fe}, \mathrm{O}$, and $\mathrm{N}$ at the region inside the red circle in Figure 13(b) are 4.20\%, 35.73\%, 57.43\%, and 2.64\%,

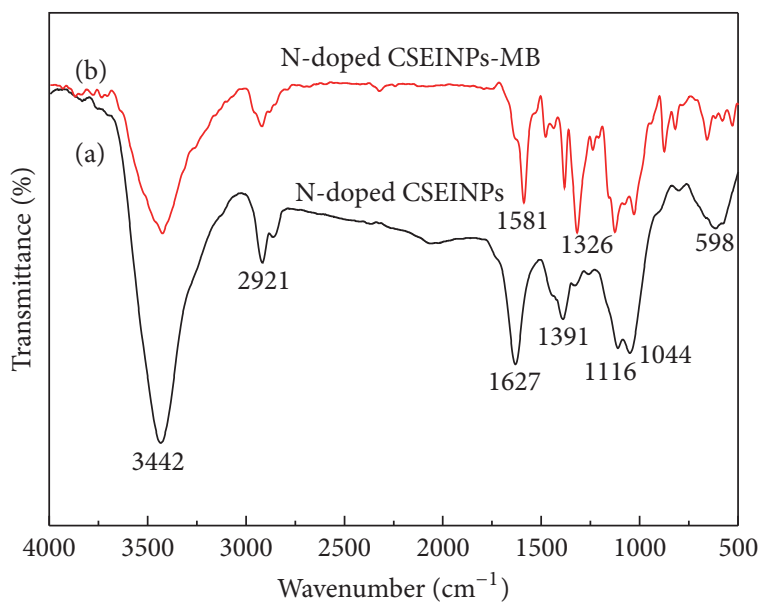

FIGURE 12: FTIR spectra of the N-doped CSEINPs (a) and N-doped CSEINPs-MB (b).

respectively (see Figure S8 in Supplementary Material); that is, the composition of the nanoparticles has also changed obviously.

The XRD pattern of the N-doped CSEINPs after being used in the recycling test is shown in Figure 14, which reveals that the phase composition includes graphitic carbon, $\mathrm{Fe}$, $\mathrm{Fe}_{3} \mathrm{C}, \mathrm{Fe}_{3} \mathrm{O}_{4}$, and Austenite $\mathrm{CFe}_{15.1}$. Compared with Figure 6, the peaks of the primary phases still exist, but the peaks of $\mathrm{Fe}_{3} \mathrm{O}_{4}$ and amorphous carbon (ca. 23 $3^{\circ}$ appear. These changes are consistent with the disappearance of the coreshell structure and the atomic percent contents of $\mathrm{C}, \mathrm{Fe}, \mathrm{O}$, and $\mathrm{N}$ elements obtained by EDX characterization (Figure S8). The reasons for the above changes of morphology, microstructure, and phase composition may be that the 


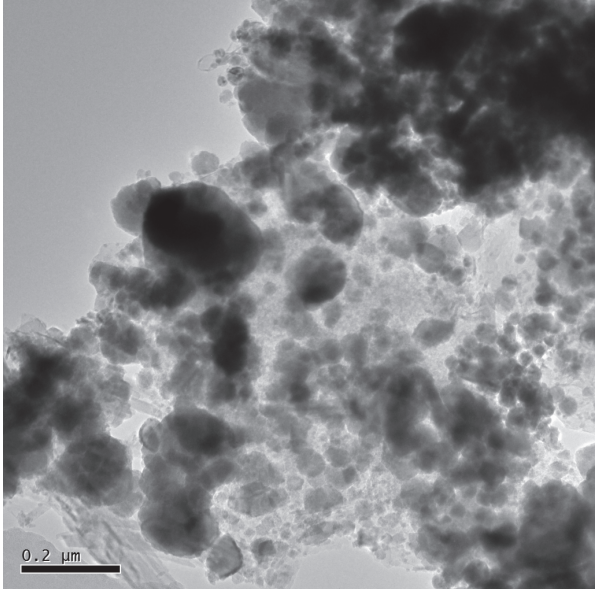

(a)

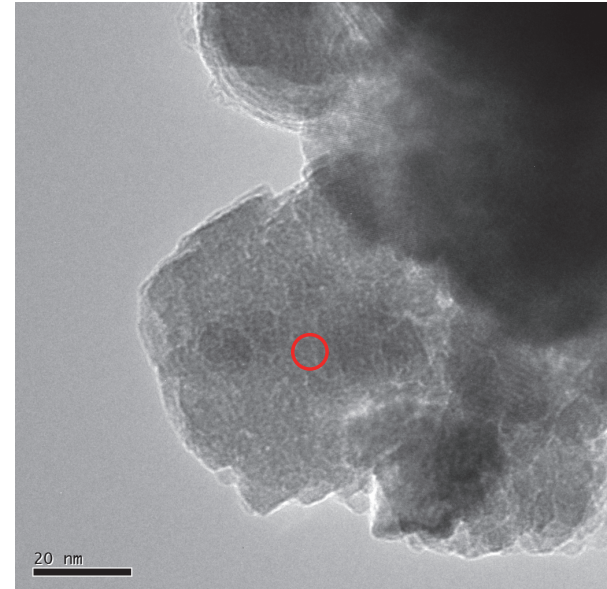

(b)

FIGURE 13: HRTEM images of the N-doped CSEINPs after being used in the recycling test.

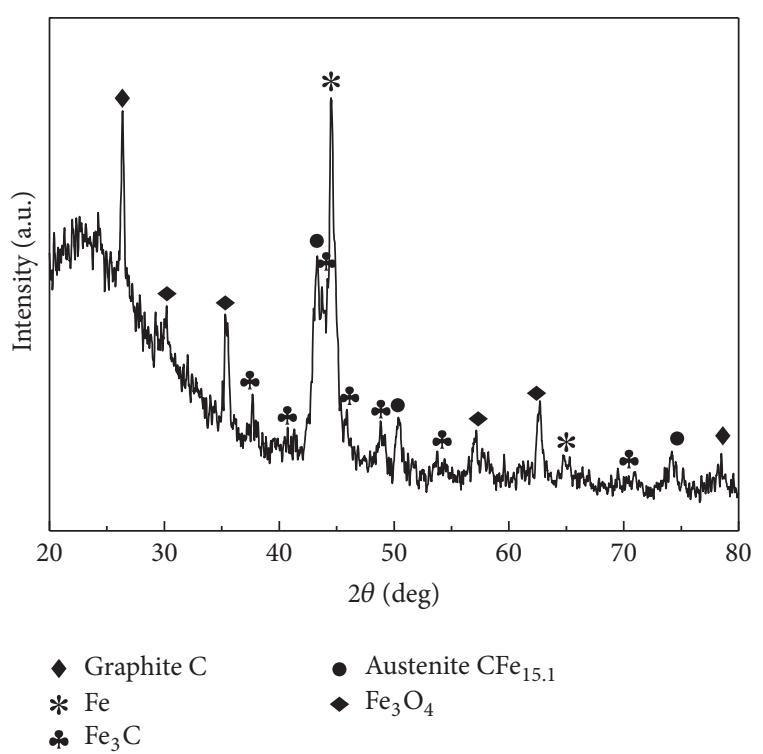

FIGURE 14: XRD pattern of the N-doped CSEINPs after being used in the recycling test $(\mathrm{Cu} \mathrm{K} \alpha)$.

interaction between the nanoparticles and $\mathrm{MB}$ molecules is strong and the core-shell structure of the nanoparticles is metastable, leading to the oxidization of $\mathrm{Fe}$ in the shell and the disappearance of the core-shell structure. Such changes may also be some of the reasons which result in the decreases of the adsorption and photocatalytic degradation abilities of the nanoparticles.

It was reported that the mechanisms of gas-liquid-solid model [52], surface diffusion [53], gas phase nucleation [54], carbon dissolution model [55], and particle self-assembling growth [56] could be used to explain the formation mechanism of some of the carbon-coated metal nanoparticles. These mechanisms have some reference significance for the understanding of the formation mechanism of $\mathrm{N}$-doped CSEINPs. On the basis of the results in the references and our experimental ones, especially those of the EELS characterization, the possible formation mechanism of $\mathrm{N}$ doped CSEINPs is supposed as follows.

During the process of arc discharge, there is a large temperature gradient between the center of arc discharge zone and the inner wall of cooling copper pipe (the average temperature gradient is about $\left.87.5-94.4^{\circ} \mathrm{C} \cdot \mathrm{mm}^{-1}[57]\right)$; under the function of arc blowing force [58], the species formed by evaporation or sublimation of the anode spread from the center of arc discharge to the surrounding space and a concentration gradient is formed. With the sharp decrease of temperature, the mixture vapor condenses to form many tiny droplets mainly containing $\mathrm{C}$ and $\mathrm{Fe}$ elements and maybe small amounts of $\mathrm{O}$ and $\mathrm{N}$ elements, most of $\mathrm{C}$ ions or atoms react with $\mathrm{Fe}$ ions or atoms to form $\mathrm{Fe}_{3} \mathrm{C}$, and small amount of $\mathrm{C}$ atoms may separate out and diffuse to the droplet surfaces; $\mathrm{N}$ ions react with $\mathrm{Fe}$ and $\mathrm{C}$ ions or atoms to form $\mathrm{Fe}_{x} \mathrm{~N}_{y}$ and $\mathrm{C}_{x} \mathrm{~N}_{y}$, respectively, and $\mathrm{O}$ ions or atoms react with $\mathrm{Fe}$ ions or atoms to form $\mathrm{Fe}_{x} \mathrm{O}_{y}$. As the droplets may be in an approximately rotating state during the process of the continued diffusion, the approximately spherical cores mainly containing $\mathrm{Fe}$ and $\mathrm{Fe}_{3} \mathrm{C}$ are formed due to the condensation of small droplets, with the further decrease of the temperature [52].

As the diameter of anode used in this work is larger about $1.6 \mathrm{~mm}$ than that reported in the reference [39] (the iron content of the former is ca. $75.5 \mathrm{wt} . \%$ (Figure S2) and that of the later is ca. $85.5 \mathrm{wt} . \%$ [39]; other experimental conditions are similar), the density of species formed by evaporation or sublimation of the anode during the process of arc discharge will increase, leading to the increase of probability of collision among the species and consequently the probability of reaction among them will increase [59]. But the increasing degree of the reaction rates between $\mathrm{C}$ and $\mathrm{Fe}, \mathrm{O}$, and $\mathrm{N}$ three elements should be significantly larger than that between $\mathrm{C}$ and $\mathrm{C}$ atoms; therefore the shell formed is the composite one containing $\mathrm{C}, \mathrm{Fe}, \mathrm{O}$, and $\mathrm{N}$ elements, rather than the one composed of graphite structure. As the 
shell surface has no obvious amorphous structure, the shell should be formed in the liquid phase or the region near to the boundary between liquid and solid phases.

Arc discharge can generate high temperature corresponding to tens of $\mathrm{eV}$ and thus some of nitrogen molecules may be dissociated (the dissociation energy of nitrogen molecule is $9.76 \mathrm{eV}$ ) [60]. According to the results of EELS characterization (Figures 4(b) and 5(b)), it is speculated that the main temperature range of $\mathrm{N}$ ions taking part in the reactions should correspond to that of formation of the region between the core-shell interface. The $\mathrm{O}$ element may be derived from the residual air in the arc discharge chamber (only a mechanical vacuum pump was used to wash the chamber), as well as the anode (Figure S1). Similarly, according to the results of EELS characterization (Figures $4(\mathrm{~b})$ and $5(\mathrm{c})$ ), the main temperature range of $\mathrm{O}$ ions or atoms taking part in the reactions is speculated to correspond to those of formation of the regions on both sides of the interface between core and shell. Although the exact temperature ranges cannot be determined by the present techniques, it is known from the above related analysis and discussion that it may be very important to modify the temperature gradient in the arc discharge chamber for controlling the composition, structure, and morphology of the products formed by DC arc discharge.

On the bases of the experimental materials, characterization results, and the above discussions, it is inferred that the following reactions may happen during the process of arc discharge:

$$
\begin{gathered}
\text { Carbon species }+\mathrm{Fe} \text { species } \longrightarrow \mathrm{Fe}_{3} \mathrm{C} \\
\text { Fe species + nitrogen ions } \longrightarrow \mathrm{Fe}_{x} \mathrm{~N}_{y} \\
\text { Fe species + oxygen species } \longrightarrow \mathrm{Fe}_{x} \mathrm{O}_{y} \\
\text { Carbon species + nitrogen ions } \longrightarrow \mathrm{C}_{x} \mathrm{~N}_{y}
\end{gathered}
$$

During the process of arc discharge, as all of the reactions may occur instantaneously and the whole system is in a dynamic nonequilibrium state, and, moreover, the temperature is very high, and it is unable to detect various intermediates of reactions and the exactly existent forms of some products can not be determined at present; the exact temperature ranges of formation of core and composite shell have yet to be verified. All these issues need to be studied further in the future.

\section{Conclusions}

In summary, we successfully prepared the N-doped CSEINPs by $\mathrm{DC}$ arc discharge under nitrogen atmosphere at $800^{\circ} \mathrm{C}$. The shells of $\mathrm{N}$-doped CSEINPs are composed of homogeneously amorphous structure containing $\mathrm{C}, \mathrm{Fe}, \mathrm{O}$, and $\mathrm{N}$ elements. The product shows typically ferromagnetic behavior at room temperature and its $M s$ and $H c$ values are $130 \mathrm{emu} / \mathrm{g}$ and 194 Oe, respectively. The adsorption capacity of MB with the N-doped CSEINPs increases from 19.9 to $44.3 \mathrm{mg} / \mathrm{g}$, with the increase of the initial concentration from 10 to $60 \mathrm{mg} / \mathrm{L}$, and ca. $90 \%$ of MB can be degraded under IVL in $150 \mathrm{~min}$. It is found that the adsorption of MB on the N-doped CSEINPs fits the pseudo-second-order kinetic model. The reusability of the as-prepared nanoparticles is not good, as only about $50 \%$ of MB can be removed with the nanoparticles in the fourth cycle. The core-shell structure of them disappears due to the interaction between them and MB molecules. This study presents a method to prepare the N-doped composite shells and thus the properties of the iron nanoparticles with core-shell structure may be easily controlled and modified. Therefore, their areas of application may be expanded further.

\section{Disclosure}

Fan Zhang's present address is Tianjin Cement Industry Design and Research Institute Co., Ltd., Tianjin 300400, China. Sayyar Ali Shah's present address is Department of Chemistry, Abdul Wali Khan University Mardan, Khyber Paktunkhwa, Pakistan.

\section{Competing Interests}

The authors declare that there is no conflict of interests regarding the publication of this paper.

\section{Acknowledgments}

Caijing Shi gratefully acknowledges Professor B. Zhang, Department of Chemistry, Tianjin University, for using UVvis spectrophotometer in his group. Associate Professor Lan Cui acknowledges the partial financial support by the National Natural Science Foundation of China (NSFC Grant no. 51076115). Associate Professor Xitao Wang acknowledges the partial financial support by the National Natural Science Foundation of China (NSFC Grant no. 21276190).

\section{References}

[1] V. Sunny, D. S. Kumar, Y. Yoshida, M. Makarewicz, W. Tabiś, and M. R. Anantharaman, "Synthesis and properties of highly stable nickel/carbon core/shell nanostructures," Carbon, vol. 48, no. 5, pp. 1643-1651, 2010.

[2] G. Li, L. Wang, W. Li, and Y. Xu, "Mesoporous Fe/C and core-shell Fe-Fe3C@C composites as efficient microwave absorbents," Microporous and Mesoporous Materials, vol. 211, article 7031, pp. 97-104, 2015.

[3] R.-J. Chung and H.-T. Shih, "Preparation of multifunctional Fe@Au core-shell nanoparticles with surface grafting as a potential treatment for magnetic hyperthermia," Materials, vol. 7, no. 2, pp. 653-661, 2014.

[4] D.-H. Kim, D. E. Nikles, and C. S. Brazel, "Synthesis and characterization of multifunctional chitosan- $\mathrm{MnFe}_{2} \mathrm{O}_{4}$ nanoparticles for magnetic hyperthermia and drug delivery," Materials, vol. 3, no. 7, pp. 4051-4065, 2010.

[5] C. Jin, Y. Wang, H. Tang, H. Wei, X. Liu, and J. Wang, "Synthesis, characterization, and catalytic applications of core-shell magnetic carbonaceous nanocomposites," Journal of Physical Chemistry C, vol. 118, no. 43, pp. 25110-25117, 2014.

[6] Z. Zhang and J. Kong, "Novel magnetic Fe3O4@C nanoparticles as adsorbents for removal of organic dyes from aqueous 
solution," Journal of Hazardous Materials, vol. 193, pp. 325-329, 2011.

[7] H. Zhang, X. Sun, X. Huang, and L. Zhou, "Encapsulation of $\alpha-\mathrm{Fe}_{2} \mathrm{O}_{3}$ nanoparticles in graphitic carbon microspheres as high-performance anode materials for lithium-ion batteries," Nanoscale, vol. 7, no. 7, pp. 3270-3275, 2015.

[8] K. E. Neo, Y. Y. Ong, H. V. Huynh, and T. S. A. Hor, "A single-molecular pathway from heterometallic $\mathrm{MM} / \mathrm{M}=\mathrm{Ba}$ II, MnII; M I = CrIII) oxalato complexes to intermetallic composite oxides," Journal of Materials Chemistry, vol. 17, no. 10, pp. 10021006, 2007.

[9] X. D. Guo, X. J. Qiao, Q. G. Ren, X. Wan, W. C. Li, and Z. G. Sun, "Synthesis and microwave-absorbing properties of $\mathrm{Co}_{3} \mathrm{Fe}_{7} @ \mathrm{C}$ core-shell nanostructure," Applied Physics A: Materials Science \& Processing, vol. 120, no. 1, pp. 43-52, 2015.

[10] N. Aguiló-Aguayo, Z. Liu, E. Bertran, and J. Yang, “Thermalinduced structural evolution of carbon-encapsulated iron nanoparticles generated by two different methods," Journal of Physical Chemistry C, vol. 117, no. 37, pp. 19167-19174, 2013.

[11] A. Malumbres, G. Martínez, R. Mallada, J. L. Hueso, O. Bomatí-Miguel, and J. Santamaría, "Continuous production of iron-based nanocrystals by laser pyrolysis. Effect of operating variables on size, composition and magnetic response," Nanotechnology, vol. 24, no. 32, Article ID 325603, 2013.

[12] P. Nautiyal, M. M. Seikh, O. I. Lebedev, and A. K. Kundu, "Solgel synthesis of Fe-Co nanoparticles and magnetization study," Journal of Magnetism and Magnetic Materials, vol. 377, pp. 402405, 2015.

[13] S. Q. Shi, W. Che, K. Liang, C. Xia, and D. Zhang, "Phase transitions of carbon-encapsulated iron oxide nanoparticles during the carbonization of cellulose at various pyrolysis temperatures," Journal of Analytical and Applied Pyrolysis, vol. 115, pp. 1-6, 2015.

[14] O. Khani, M. Z. Shoushtari, and M. Farbod, "Excellent improvement in the static and dynamic magnetic properties of carbon coated iron nanoparticles for microwave absorption," Physica B: Condensed Matter, vol. 477, pp. 33-39, 2015.

[15] L. S. Zhang, L. Cui, F. Zhang et al., "Preparation of carbon encapsulated iron nanoparticles with composite shell by DC arc discharge," Chemistry \& Bioengineering, vol. 31, no. 6, pp. 50-54, 2014 (Chinese).

[16] J. C. Kim, S. J. Kim, Y. D. Kim, J. S. Kim, and C. J. Choi, "Formation and some properties of Fe core-shell powders with experimental parameters of the chemical vapor condensation process," Journal of Alloys and Compounds, vol. 483, no. 1-2, pp. 359-362, 2009.

[17] L. Zhang, X. Yang, and Y. Wu, "Synthesis of $\mathrm{Fe}_{3} \mathrm{O}_{4} @ \mathrm{SiO}_{2} @$ $\mathrm{MnO}_{2}$ composite magnetic submicrospheres as adsorbent for methyl orange decolouration," Micro and Nano Letters, vol. 10, no. 1, pp. 12-15, 2015.

[18] T. Liu, Y. Li, Q. Du et al., "Adsorption of methylene blue from aqueous solution by graphene," Colloids and Surfaces B: Biointerfaces, vol. 90, no. 1, pp. 197-203, 2012.

[19] B. H. Hameed, A. T. M. Din, and A. L. Ahmad, "Adsorption of methylene blue onto bamboo-based activated carbon: kinetics and equilibrium studies," The Journal of Hazardous Materials, vol. 141, no. 3, pp. 819-825, 2007.

[20] L. Qu, T. Han, Z. Luo, C. Liu, Y. Mei, and T. Zhu, "Onestep fabricated $\mathrm{Fe}_{3} \mathrm{O}_{4} @ \mathrm{C}$ core-shell composites for dye removal: kinetics, equilibrium and thermodynamics," Journal of Physics and Chemistry of Solids, vol. 78, pp. 20-27, 2015.
[21] X. Wang, P. Zhang, W. Wang, X. Lei, B. Zou, and H. Yang, "Synthesis, structure and magnetic properties of graphite carbon encapsulated $\mathrm{Fe}_{3} \mathrm{C}$ nanoparticles for applications as adsorbents," RSC Advances, vol. 5, no. 35, pp. 27857-27861, 2015.

[22] S. Bai, X. Shen, X. Zhong et al., "One-pot solvothermal preparation of magnetic reduced graphene oxide-ferrite hybrids for organic dye removal," Carbon, vol. 50, no. 6, pp. 2337-2346, 2012.

[23] A. M. Mansour, "Photocatalytic degradation of methylene blue with hematite nanoparticles synthesized by thermal decomposition of fluoroquinolones oxalato-iron(III) complexes," RSC Advances, vol. 5, no. 76, pp. 62052-62061, 2015.

[24] J. Rashid, M. A. Barakat, Y. Ruzmanova, and A. Chianese, " $\mathrm{Fe}_{3} \mathrm{O}_{4} / \mathrm{SiO}_{2} / \mathrm{TiO}_{2}$ nanoparticles for photocatalytic degradation of 2-chlorophenol in simulated wastewater," Environmental Science and Pollution Research, vol. 22, no. 4, pp. 3149-3157, 2015.

[25] S. Cui, P. Scharff, C. Siegmund et al., "Investigation on preparation of multiwalled carbon nanotubes by DC arc discharge under $\mathrm{N}_{2}$ atmosphere," Carbon, vol. 42, no. 5-6, pp. 931-939, 2004.

[26] S. A. Shah, L. Cui, K. Lin et al., "Preparation of novel silicon/ nitrogen-doped graphene composite nanosheets by DC arc discharge," RSC Advances, vol. 5, no. 37, pp. 29230-29237, 2015.

[27] R. Li, J. Yu, A. Shah et al., "Novel in situ synthesized Fe@C magnetic nanocapsules used as adsorbent for removal of organic dyes and its recycling," Nano, vol. 11, no. 2, Article ID 1650013, 12 pages, 2016.

[28] B. Li, X. L. Song, and P. Zhang, "Raman-assessed structural evolution of as-deposited few-layer graphene by $\mathrm{He} / \mathrm{H}_{2}$ arc discharge during rapid-cooling thinning treatment," Carbon, vol. 66, pp. 426-435, 2014.

[29] F. Liang, M. Tanaka, S. Choi, and T. Watanabe, "Measurement of anode surface temperature in carbon nanomaterial production by arc discharge method," Materials Research Bulletin, vol. 60, pp. 158-165, 2014.

[30] K. Ghosh, M. Kumar, T. Maruyama, and Y. Ando, "Microstructural, electron-spectroscopic and field-emission studies of carbon nitride nanotubes grown from cage-like and linear carbon sources," Carbon, vol. 47, no. 6, pp. 1565-1575, 2009.

[31] M. Glerup, J. Steinmetz, D. Samaille et al., "Synthesis of Ndoped SWNT using the arc-discharge procedure," Chemical Physics Letters, vol. 387, no. 1-3, pp. 193-197, 2004.

[32] C. Colliex, T. Manoubi, and C. Ortiz, "Electron-energy-lossspectroscopy near-edge fine structures in the iron-oxygen system," Physical Review B, vol. 44, no. 20, pp. 11402-11411, 1991.

[33] C. Wang, D. R. Baer, J. E. Amonette, M. H. Engelhard, J. Antony, and Y. Qiang, "Morphology and electronic structure of the oxide shell on the surface of iron nanoparticles," Journal of the American Chemical Society, vol. 131, no. 25, pp. 8824-8832, 2009.

[34] L. Yedra, E. Xuriguera, M. Estrader et al., "Oxide wizard: an EELS application to characterize the white lines of transition metal edges," Microscopy and Microanalysis, vol. 20, no. 3, pp. 698-705, 2014.

[35] X. Liu, S. W. Or, Y. Sun et al., "Influence of a graphite shell on the thermal, magnetic and electromagnetic characteristics of Fe nanoparticles," Journal of Alloys and Compounds, vol. 548, pp. 239-244, 2013.

[36] X. F. Zhang, X. L. Dong, H. Huang, D. K. Wang, B. Lv, and J. P. Lei, "High permittivity from defective carbon-coated $\mathrm{Cu}$ nanocapsules," Nanotechnology, vol. 18, no. 27, Article ID 275701, 2007. 
[37] D. Chaira, B. K. Mishra, and S. Sangal, "Efficient synthesis and characterization of iron carbide powder by reaction milling," Powder Technology, vol. 191, no. 1-2, pp. 149-154, 2009.

[38] M. Bystrzejewski, A. Huczko, H. Lange et al., "Large scale continuous synthesis of carbon-encapsulated magnetic nanoparticles," Nanotechnology, vol. 18, no. 14, Article ID 145608, 2007.

[39] F. Zhang, L. Cui, K. Lin et al., "Preparation of carbonencapsulated iron nanoparticles in high yield by DC arc discharge and their characterization," Journal of Alloys and Compounds, vol. 553, pp. 367-374, 2013.

[40] J. Liu, B. Yu, Q. Zhang et al., "Synthesis and magnetic properties of $\mathrm{Fe}_{3} \mathrm{C}-\mathrm{C}$ core-shell nanoparticles," Nanotechnology, vol. 26, no. 8, Article ID 085601, 2015.

[41] S. Bhattacharyya, "Iron nitride family at reduced dimensions: A review of their synthesis protocols and structural and magnetic properties," Journal of Physical Chemistry C, vol. 119, no. 4, pp. 1601-1622, 2015.

[42] J. Borysiuk, A. Grabias, J. Szczytko, M. Bystrzejewski, A. Twardowski, and H. Lange, "Structure and magnetic properties of carbon encapsulated Fe nanoparticles obtained by arc plasma and combustion synthesis," Carbon, vol. 46, no. 13, pp. 16931701, 2008.

[43] M. Bystrzejewski and A. Grabias, "Tailoring phase composition in carbon-encapsulated iron nanoparticles," Materials Characterization, vol. 62, no. 1, pp. 152-156, 2011.

[44] S. Taketomi, A. J. Shapiro, and R. D. Shull, "Structural effects on the magnetic character of yttrium-iron-garnet nanoparticles dispersed in glass composites," Journal of Applied Physics, vol. 93, no. 10, pp. 7199-7201, 2003.

[45] C. Ma, B. Luo, H.-H. Song, and L.-J. Zhi, "Preparation of carbon-encapsulated metal magnetic nanoparticles by an instant pyrolysis method," New Carbon Materials, vol. 25, no. 3, pp. 199-204, 2010.

[46] M. Bystrzejewski, Z. Károly, J. Szépvölgyi, A. Huczko, and H. Lange, "Continuous synthesis of controlled size carbonencapsulated iron nanoparticles," Materials Research Bulletin, vol. 46, no. 12, pp. 2408-2417, 2011.

[47] U. Weissker, M. Löffler, F. Wolny et al., "Perpendicular magnetization of long iron carbide nanowires inside carbon nanotubes due to magnetocrystalline anisotropy," Journal of Applied Physics, vol. 106, no. 5, Article ID 054909, 2009.

[48] G. K. Ramesha, A. V. Kumara, H. B. Muralidhara, and S. Sampath, "Graphene and graphene oxide as effective adsorbents toward anionic and cationic dyes," Journal of Colloid and Interface Science, vol. 361, no. 1, pp. 270-277, 2011.

[49] Y. Yukselen and A. Kaya, "Suitability of the methylene blue test for surface area, cation exchange capacity and swell potential determination of clayey soils," Engineering Geology, vol. 102, no. 1-2, pp. 38-45, 2008.

[50] Q. Chen and Q. Wu, "Preparation of carbon microspheres decorated with silver nanoparticles and their ability to remove dyes from aqueous solution," The Journal of Hazardous Materials, vol. 283, pp. 193-201, 2015.

[51] L. I. Cabrera, M. Martínez, D. Reyman, P. Crespo, M. P. Morales, and P. Herrasti, "One single-step synthesis of multifunctional methylene blue-coated magnetite nanoparticles," Journal of Nanoparticle Research, vol. 13, no. 12, pp. 6931-6939, 2011.

[52] M. Bystrzejewski, "Synthesis of carbon-encapsulated iron nanoparticles via solid state reduction of iron oxide nanoparticles," Journal of Solid State Chemistry, vol. 184, no. 6, pp. 14921498, 2011.
[53] T. Sagara, S. Kurumi, and K. Suzuki, "Growth of linear Nifilled carbon nanotubes by local arc discharge in liquid ethanol," Applied Surface Science, vol. 292, pp. 39-43, 2014.

[54] K. Tulugan, H. Kim, Y. Choi, and W. Park, "Aluminum-silicon and aluminum-silicon/carbon nanoparticles with core-shell structure synthesized by arc discharge method," Journal of Alloys and Compounds, vol. 579, pp. 529-532, 2013.

[55] Y.-L. Hsin, C.-F. Lin, Y.-C. Liang et al., "Microwave arcing induced formation and growth mechanisms of core/shell metal/carbon nanoparticles in organic solutions," Advanced Functional Materials, vol. 18, no. 14, pp. 2048-2056, 2008.

[56] Y. Yang, X. Liu, and B. Xu, "Fe-encapsulating carbon nano onionlike fullerenes from heavy oil residue," Journal of Materials Research, vol. 23, no. 5, pp. 1393-1397, 2008.

[57] L. Li, K. Lin, F. Zhang et al., "Preparation of N-doped long bamboo-like carbon nanotubes and their growth mechanism," Chinese Journal of Inorganic Chemistry, vol. 30, no. 5, pp. 10971103, 2014.

[58] Y. Chen, S. Dong, S. Li, Y. Liu, and W. Yan, "Preparation and growth of $\mathrm{N}$-doped hollow carbon nanospheres and their application as catalyst support in direct borohydride fuel cell," Journal of Nanoscience and Nanotechnology, vol. 15, no. 5, pp. 3862-3869, 2015.

[59] M. Groppi and G. Spiga, "A Bhatnagar-Gross-Krook-type approach for chemically reacting gas mixtures," Physics of Fluids, vol. 16, no. 12, pp. 4273-4284, 2004.

[60] W.-D. Yang, P.-N. Wang, Z.-P. Liu, L. Mi, S.-C. Chen, and F.M. Li, "Enhanced dissociation and ionization of $\mathrm{N}_{2}$ in a pulsed discharge by adding $\mathrm{NH}_{3}$ or $\mathrm{CH}_{4}$ into nitrogen gas," Journal of Physics D: Applied Physics, vol. 33, no. 24, pp. 3223-3227, 2000. 

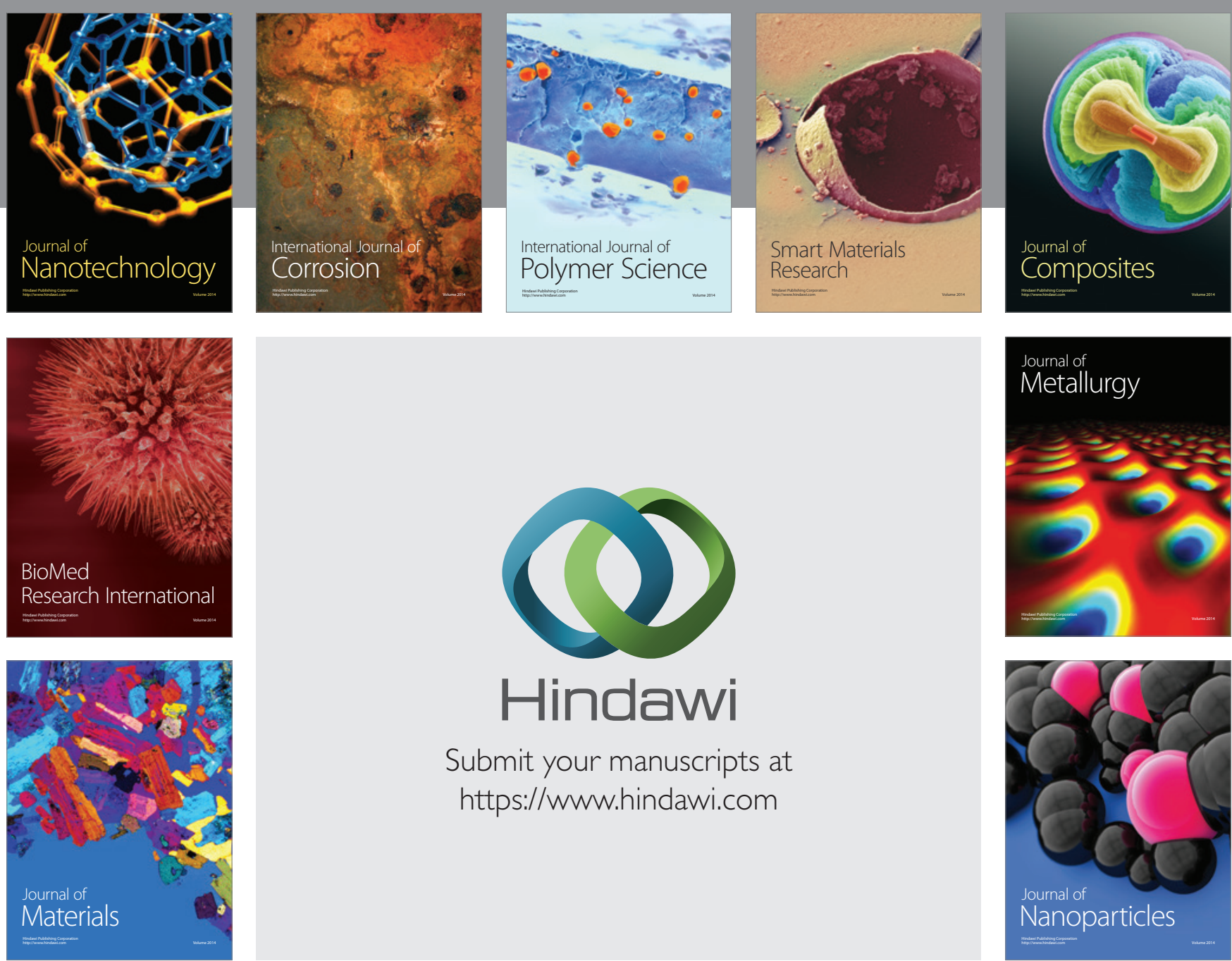

\section{Hindawi}

Submit your manuscripts at

https://www.hindawi.com

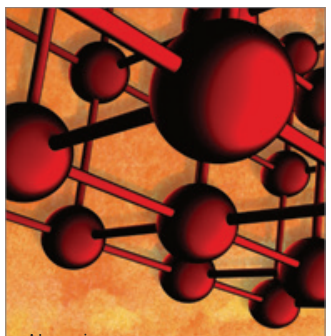

Materials Science and Engineering
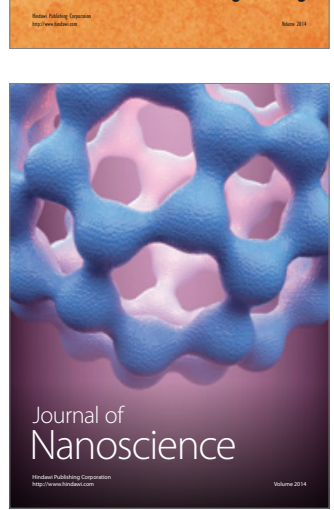
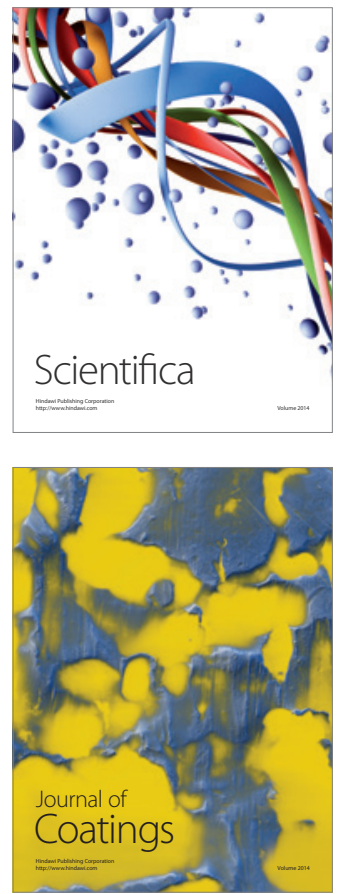
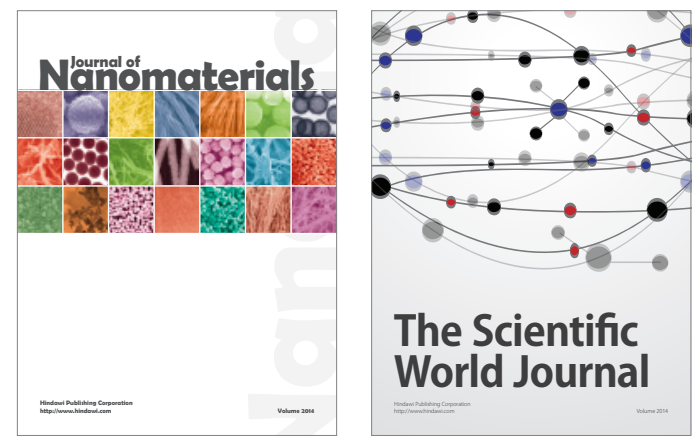

The Scientific World Journal
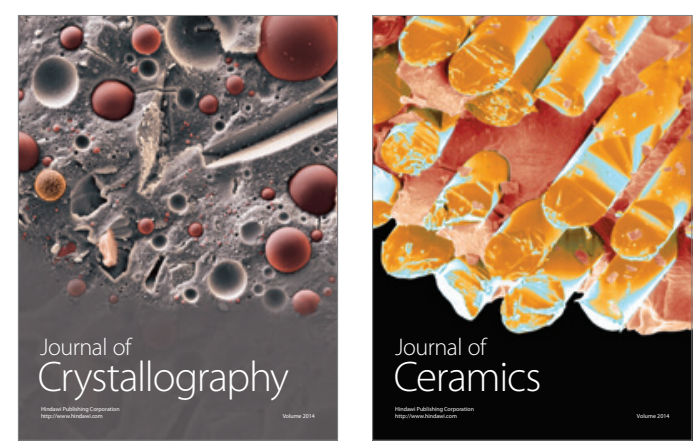
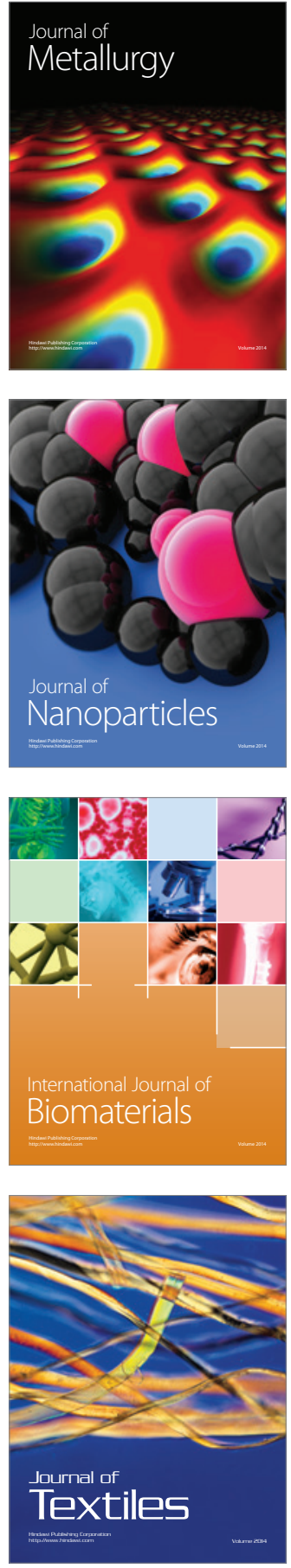